\title{
Structure-Activity Relationship Studies on Oxazolo[3,4-a]Pyrazine Derivatives Leading to the Discovery of a Novel Neuropeptide $S$ Receptor Antagonist With Potent In Vivo Activity
}

\author{
Valentina Albanese ${ }^{1 \#}$, Chiara Ruzza ${ }^{2,3 \#}$, Erika Marzola ${ }^{1}$, Tatiana Bernardi ${ }^{1}$, Martina Fabbri ${ }^{1}$, \\ Anna Fantinati ${ }^{1}$, Claudio Trapella ${ }^{1,3}$, Rainer K. Reinscheid ${ }^{4,5}$, Federica Ferrari ${ }^{2}$, Chiara Sturaro ${ }^{2}$, \\ Girolamo Calò $^{6}$, Giorgio Amendola ${ }^{7}$, Sandro Cosconati ${ }^{7 *}$, Salvatore Pacifico ${ }^{1 *}$, Remo Guerrini ${ }^{1,3}$ \\ and Delia Preti. ${ }^{1}$ \\ ${ }^{1}$ Department of Chemical, Pharmaceutical and Agricultural Sciences, University of Ferrara, \\ Via Luigi Borsari 46, 44121 Ferrara, Italy. ${ }^{2}$ Department of Neuroscience and Rehabilitation, \\ Section of Pharmacology, University of Ferrara Via Fossato di Mortara 17/19, 44121 Ferrara, \\ Italy. ${ }^{3}$ Technopole of Ferrara, LTTA Laboratory for Advanced Therapies, Ferrara, Italy. ${ }^{4}$ \\ Institute of Pharmacology and Toxicology, Jena University Hospital, Friedrich Schiller \\ University, Jena, Germany. ${ }^{5}$ Institute of Physiology I, University Hospital Münster, University \\ of Münster, Münster, Germany. ${ }^{6}$ Department of Pharmaceutical and Pharmacological Sciences, \\ University of Padova, Largo Meneghetti, 2 - 35131 Padova, Italy. 7 "DiSTABiF", Università \\ della Campania "Luigi Vanvitelli”, Via Vivaldi 43, 81100 Caserta, Italy.
}

\section{SUPPORTING INFORMATION}

\begin{tabular}{|l|c|}
\hline CONTENTS & Pag. \\
\hline Figures S1-S2: ${ }^{1}$ H-NMR and NOE NMR analysis for compound 17 & S2-S3 \\
\hline $\begin{array}{l}\text { Table S1: Human GPCRs sharing with NPSR a sequence identity higher than } \\
\text { 20\%, a sequence coverage higher than 70\%, and that were crystallized in their } \\
\text { inactive states. }\end{array}$ & S4 \\
\hline $\begin{array}{l}\text { Figure S3: Phylogenetic tree of the human NPSR and the six selected human } \\
\text { GPCRs used as template structures. }\end{array}$ & S5 \\
\hline $\begin{array}{l}\text { Figures S4-S9: pairwise sequence alignments of the human NPSR and the six } \\
\text { selected human GPCRs used as template structures. }\end{array}$ \\
\hline $\begin{array}{l}\text { Figures S10-S15: Ligand Root Mean Square Fluctuation (RMSF) of compounds } \\
\text { 1, 16 and 21 }\end{array}$ & S12-S14 \\
\hline Figures S16-S27: Ligand-NPSR interactions for compounds 1, 16 and 21 & S15-S26 \\
\hline HPLC traces of the final compounds 3-21 & S27-S36 \\
\hline
\end{tabular}



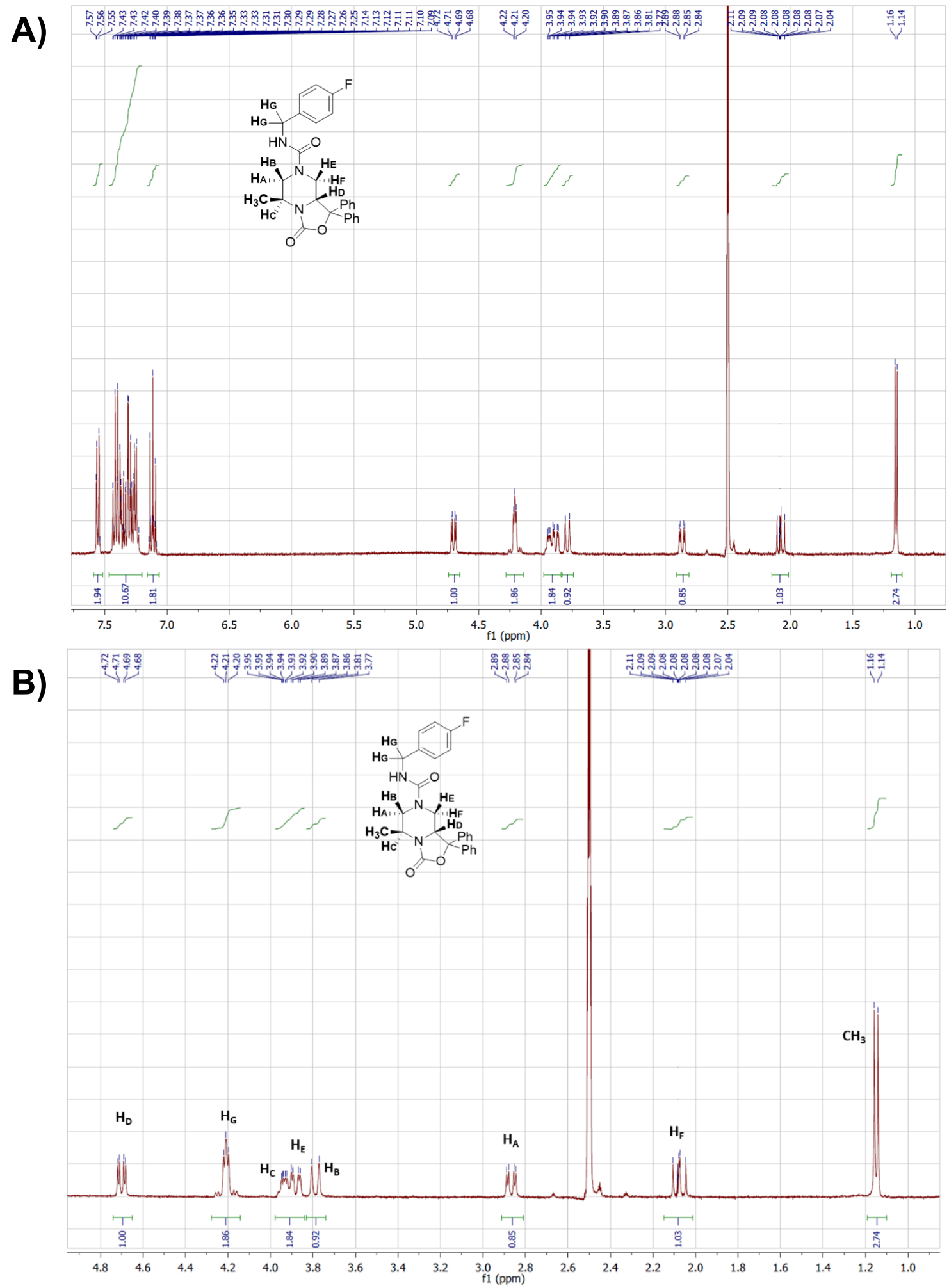

Figure S1. A) Full ${ }^{1} \mathrm{H}-\mathrm{NMR}$ spectrum of compound 17; B) Aliphatic region of the ${ }^{1} \mathrm{H}-\mathrm{NMR}$ spectrum of compound $\mathbf{1 7}$ with proton assignments. 


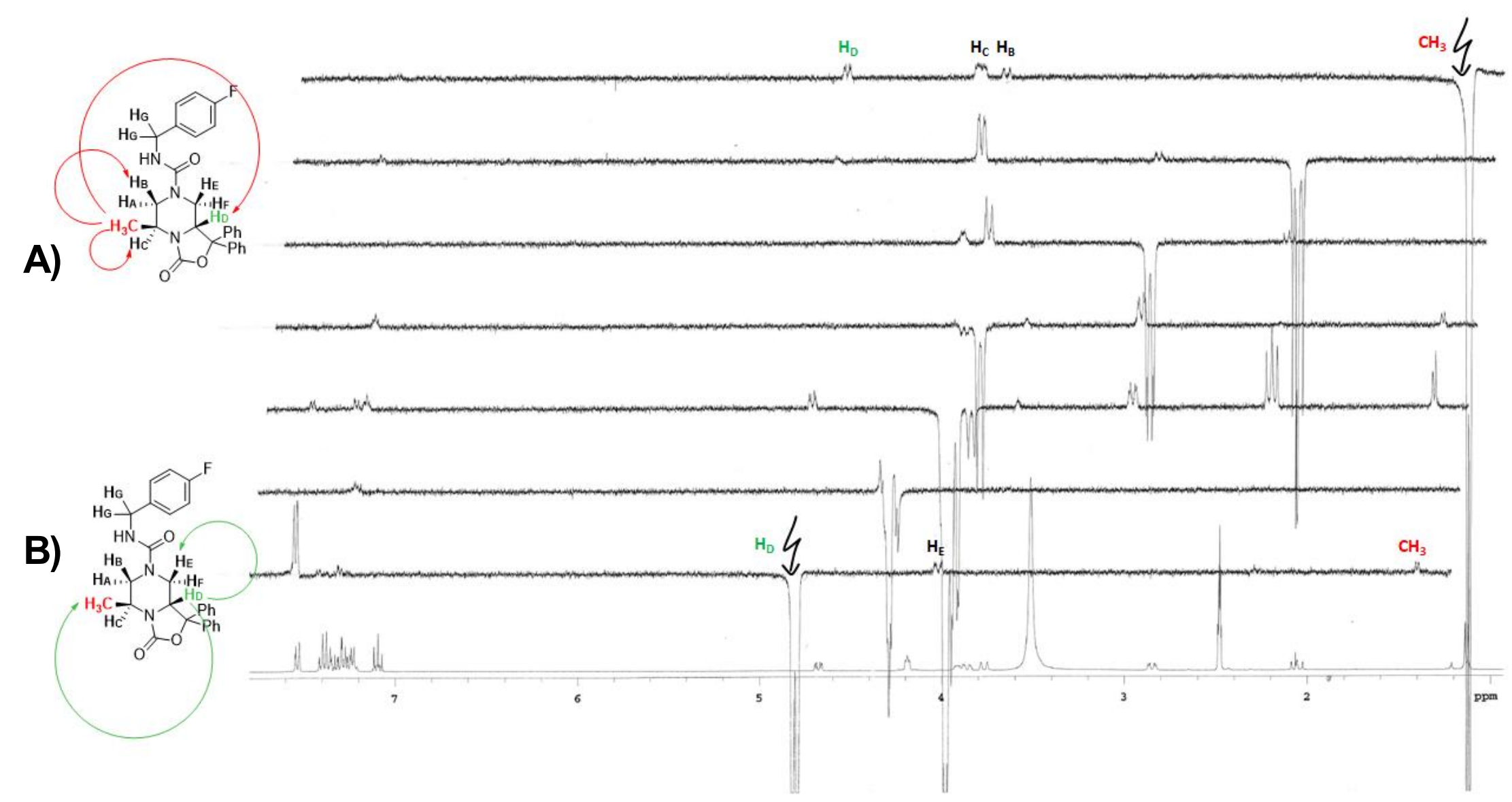

Figure S2. NOE ${ }^{1} \mathrm{H}-\mathrm{NMR}$ analysis of compound 17. A) Red arrows indicate that, as visible in the upper trace, irradiating the $\mathrm{CH}_{3}$ protons produced an enhancement of the signals of $\mathbf{H C}_{\mathbf{C}}$ (geminal proton), $\mathbf{H}_{\mathbf{B}}$ and $\mathbf{H}_{\mathbf{D}}$ (that have a syn relationship with the irradiated methyl group). B) The green arrows show that the irradiation of $\mathrm{HD}$, produced an enhancement of the signals of the $\mathrm{CH}_{3}$ protons and of HE that have a syn relationship with HD (see the bottom trace). 
Table S1. Human GPCRs sharing with NPSR a sequence identity higher than $20 \%$, a sequence coverage higher than $70 \%$, and that were crystallized in their inactive states.

\begin{tabular}{|c|c|c|c|c|}
\hline Receptor & Considered PDB & $\begin{array}{l}\text { Query } \\
\text { Coverage }\end{array}$ & $\begin{array}{l}\text { Sequence } \\
\text { Identity }\end{array}$ & $\begin{array}{l}\text { ECL2 } \\
\text { conformatio } \\
\text { n }\end{array}$ \\
\hline $\begin{array}{l}\text { Human } \mathrm{C} 5 \mathrm{a} \\
\text { anaphylatoxin chemotactic } \\
\text { receptor } 1\end{array}$ & $6 \mathrm{C} 1 \mathrm{R}$ & $79 \%$ & $23 \%$ & $\beta$-hairpin \\
\hline $\begin{array}{l}\text { Human CC chemokine } \\
\text { receptor type } 9\end{array}$ & 5LWE & $73 \%$ & $21 \%$ & Not Present \\
\hline Human $\kappa$ opioid receptor & 4DJH & $73 \%$ & $24 \%$ & $\beta$-hairpin \\
\hline $\begin{array}{l}\text { Human M2 muscarinic } \\
\text { receptor }\end{array}$ & $5 \mathrm{ZKC}$ & $74 \%$ & $26 \%$ & Random Coil \\
\hline $\begin{array}{l}\text { Human Neuropeptide Y } \\
\text { Y1 Receptor }\end{array}$ & $5 \mathrm{ZBH}$ & $76 \%$ & $22 \%$ & $\beta$-hairpin \\
\hline Human orexin-1 receptor & 6TOD & $75 \%$ & $22 \%$ & $\beta$-hairpin \\
\hline $\begin{array}{l}\text { Human type- } 2 \text { angiotensin } \\
\text { receptor }\end{array}$ & 4ZUD & $74 \%$ & $26 \%$ & $\beta$-hairpin \\
\hline
\end{tabular}




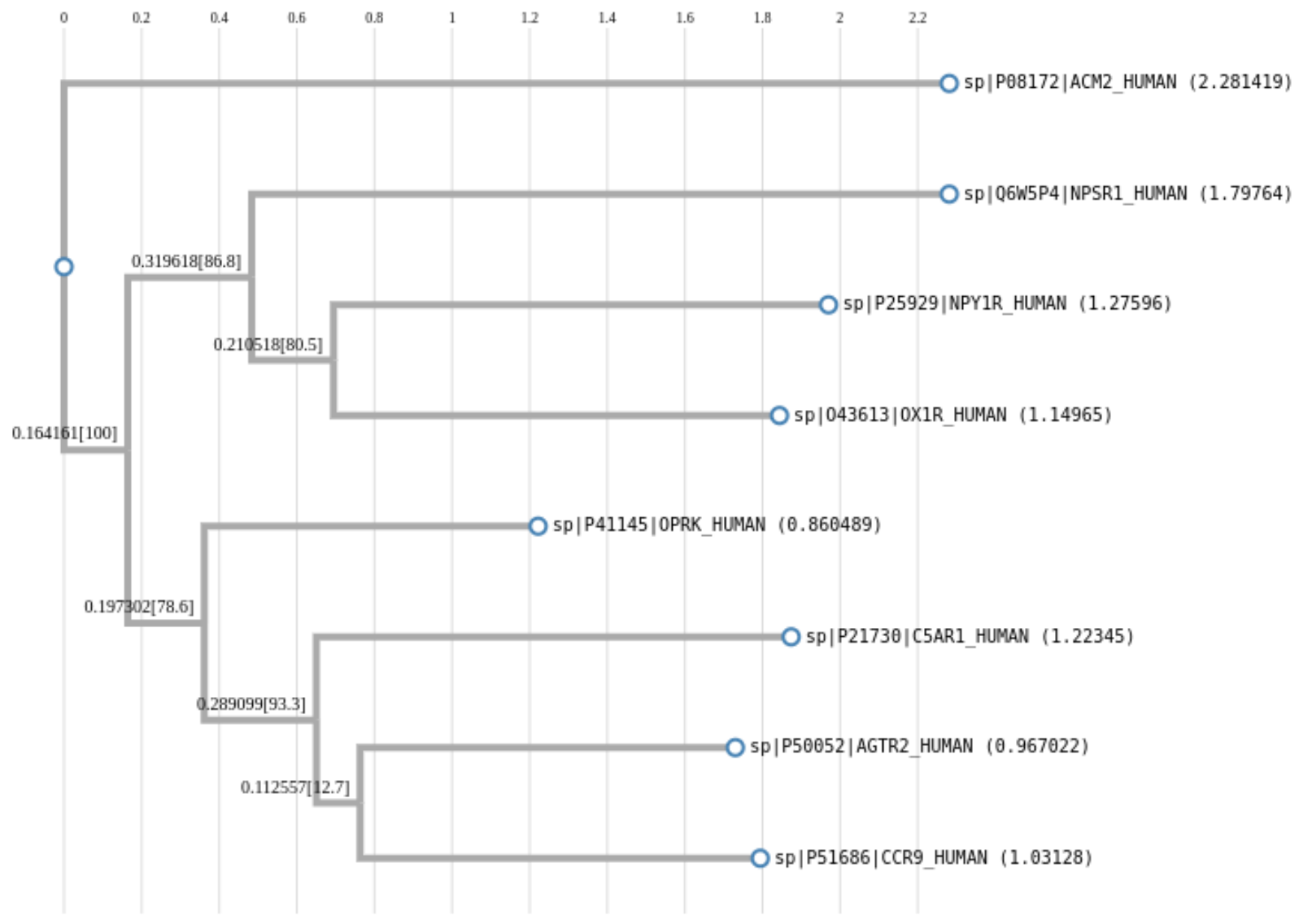

Figure S3. Phylogenetic tree of the human NPSR and the six selected human GPCRs used as template structures. 


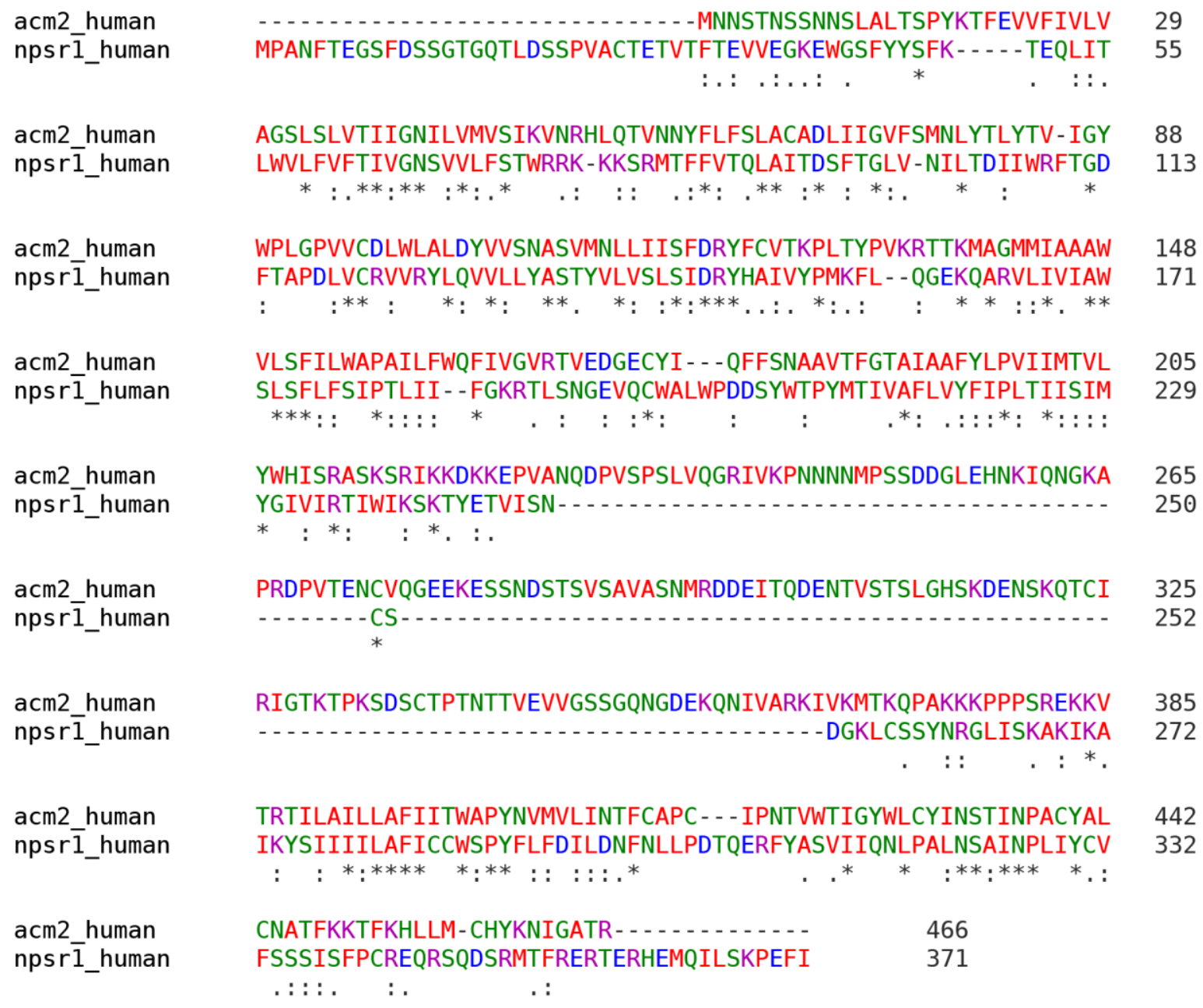

Figure S4. Pairwise sequence alignment as calculated through the gpcrdb.org webserver between human M2 muscarinic receptor and the human neuropeptide S receptor. 


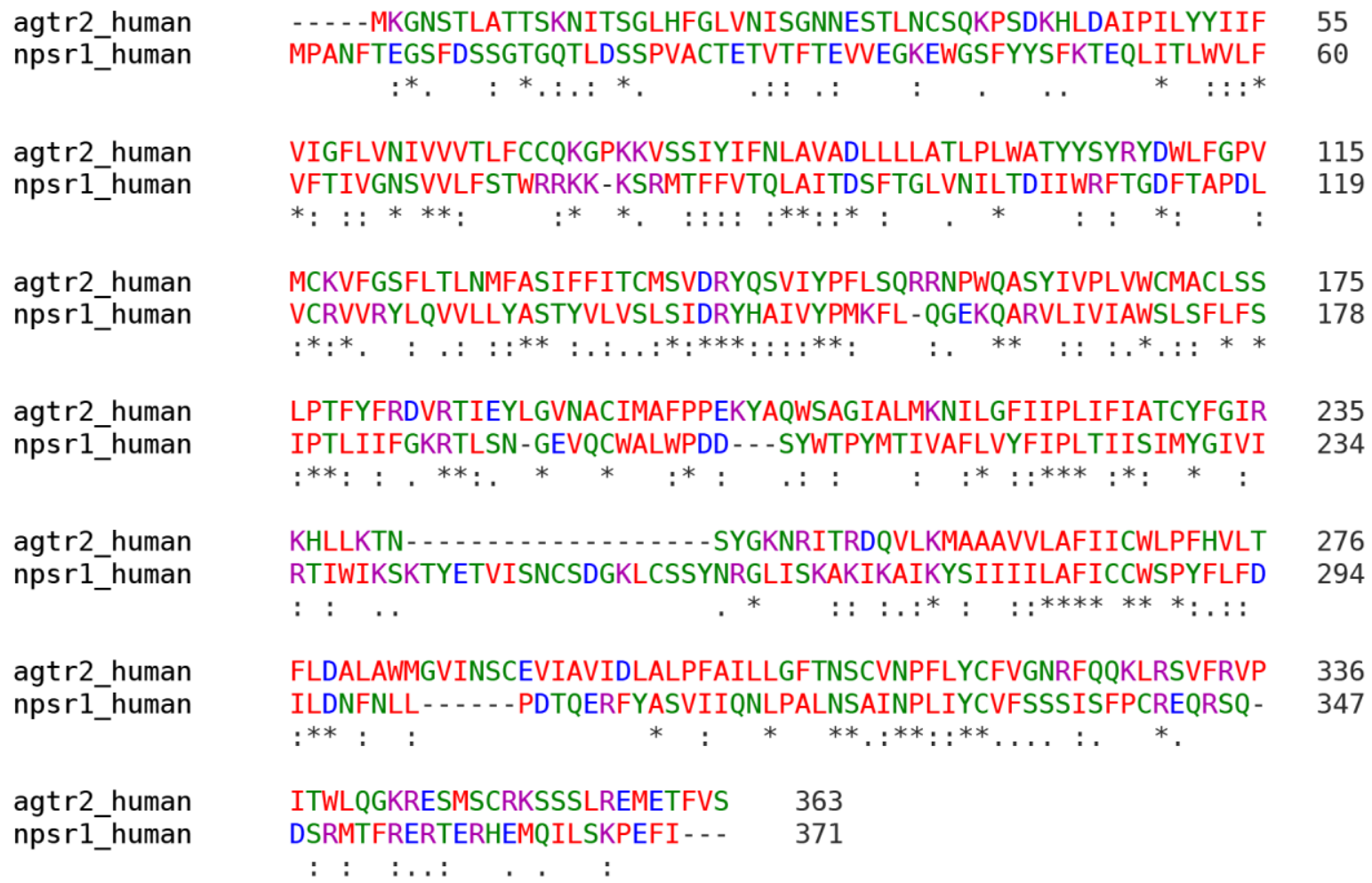

Figure S5. Pairwise sequence alignment as calculated through the gpcrdb.org webserver between human type- 2 angiotensin receptor and the human neuropeptide $\mathrm{S}$ receptor. 


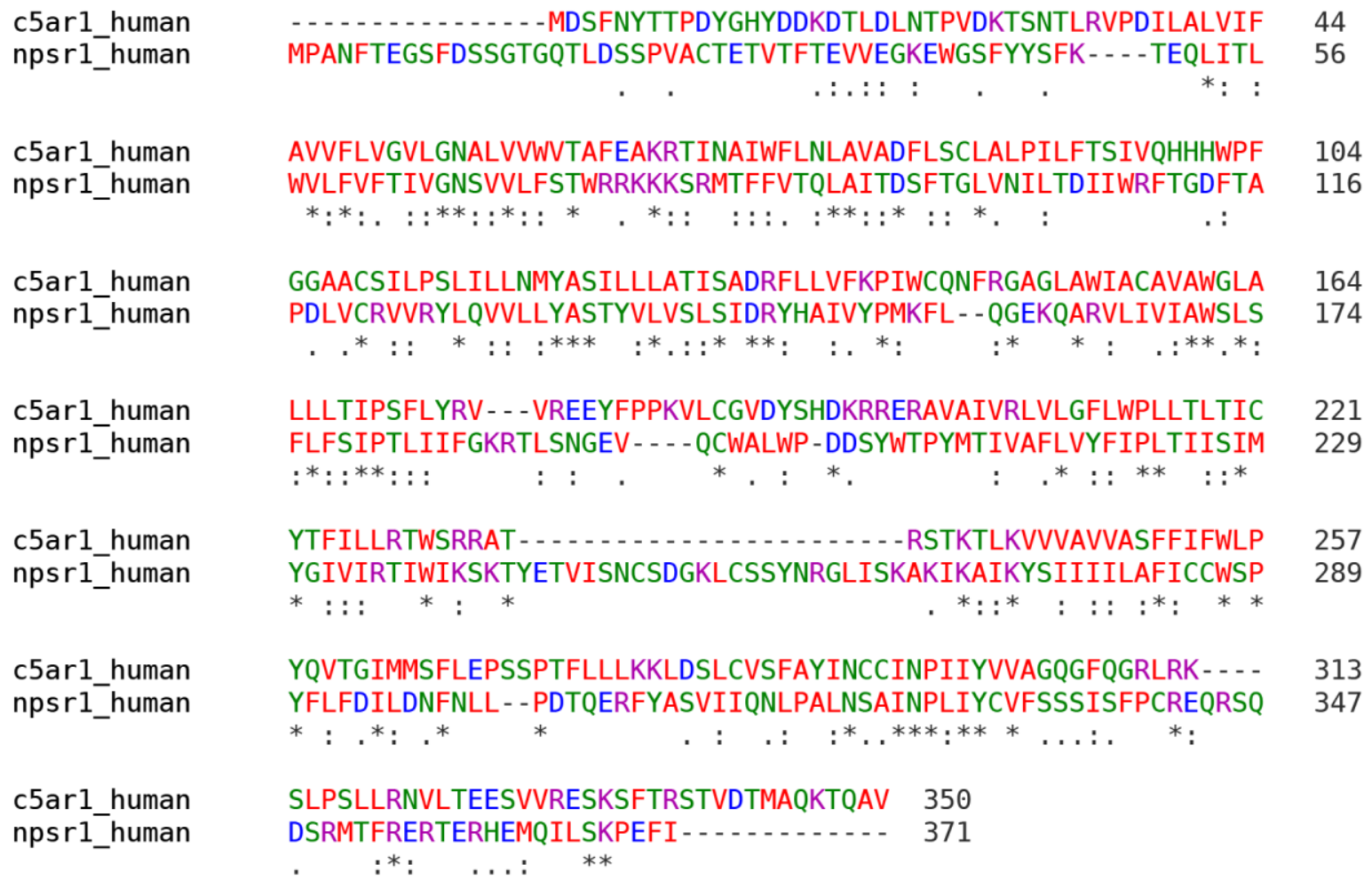

Figure S6. Pairwise sequence alignment as calculated through the gpcrdb.org webserver between human $\mathrm{C} 5 \mathrm{a}$ anaphylatoxin chemotactic receptor 1 and the human neuropeptide $\mathrm{S}$ receptor. 


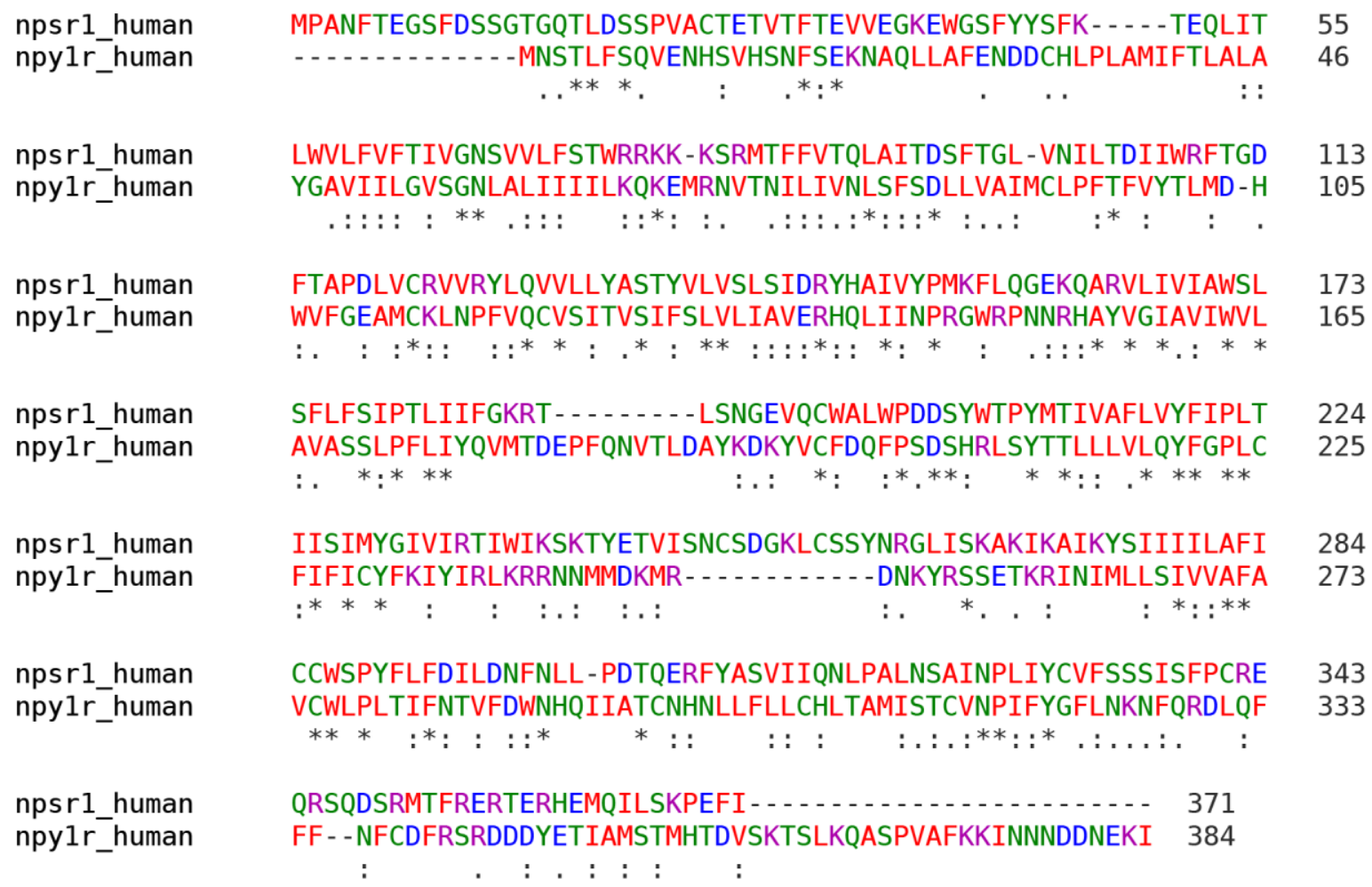

Figure S7. Pairwise sequence alignment as calculated through the gpcrdb.org webserver between human neuropeptide Y Y1 receptor and the human neuropeptide S receptor. 


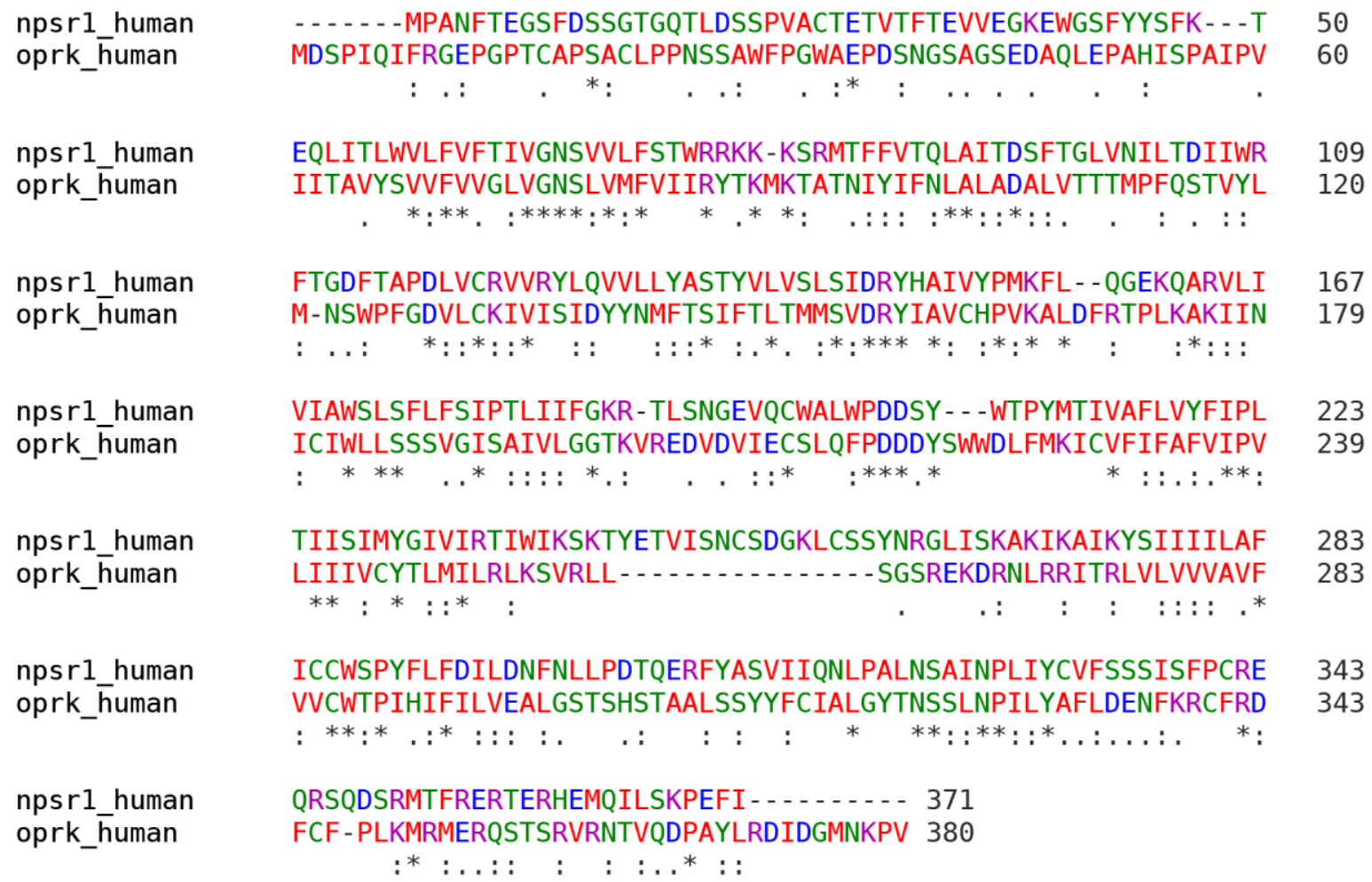

Figure S8. Pairwise sequence alignment as calculated through the gpcrdb.org webserver between human $\kappa$ opioid receptor and the human neuropeptide $\mathrm{S}$ receptor. 


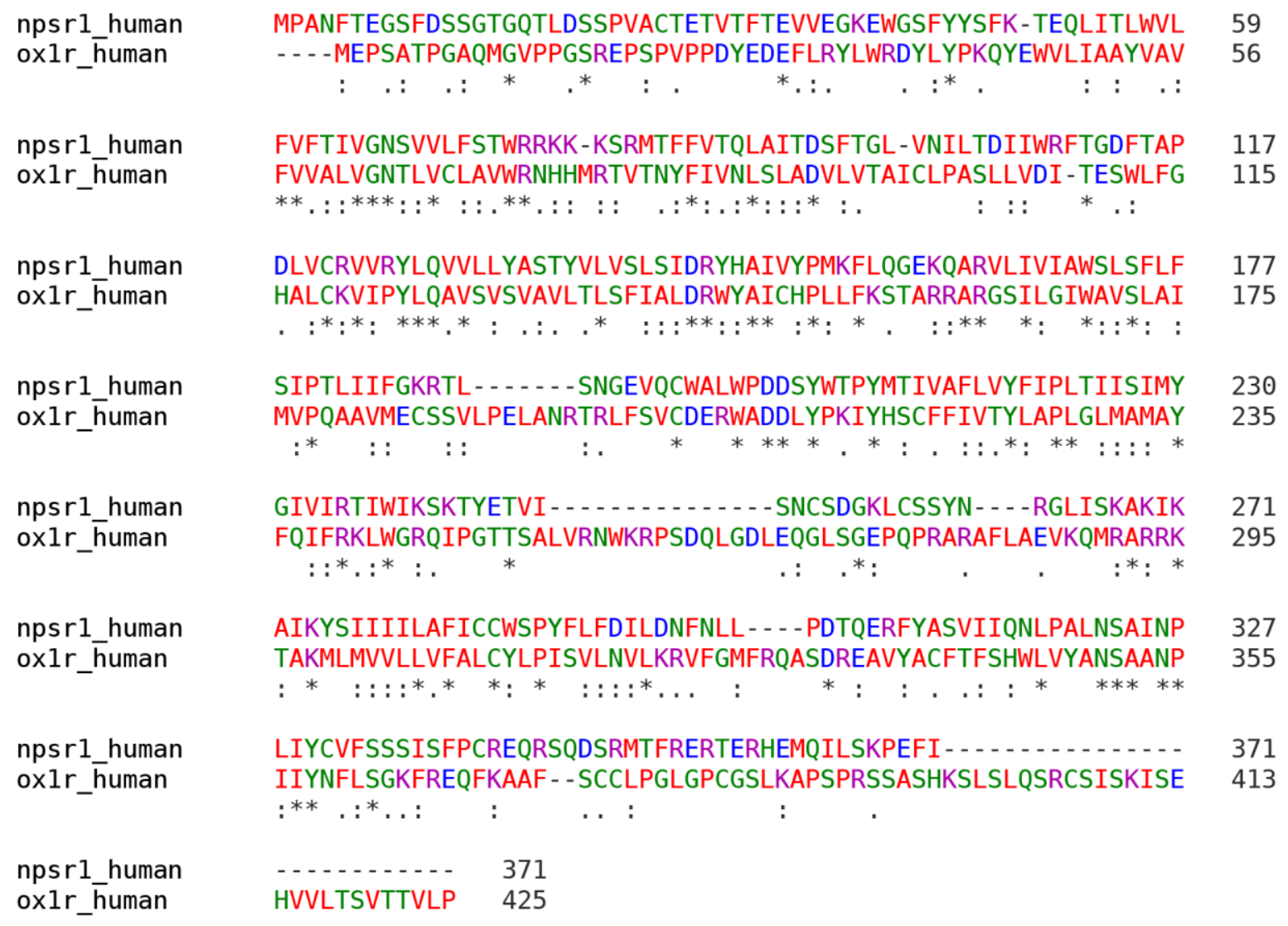

Figure S9. Pairwise sequence alignment as calculated through the gpcrdb.org webserver between human orexin-1 receptor and the human neuropeptide $\mathrm{S}$ receptor. 

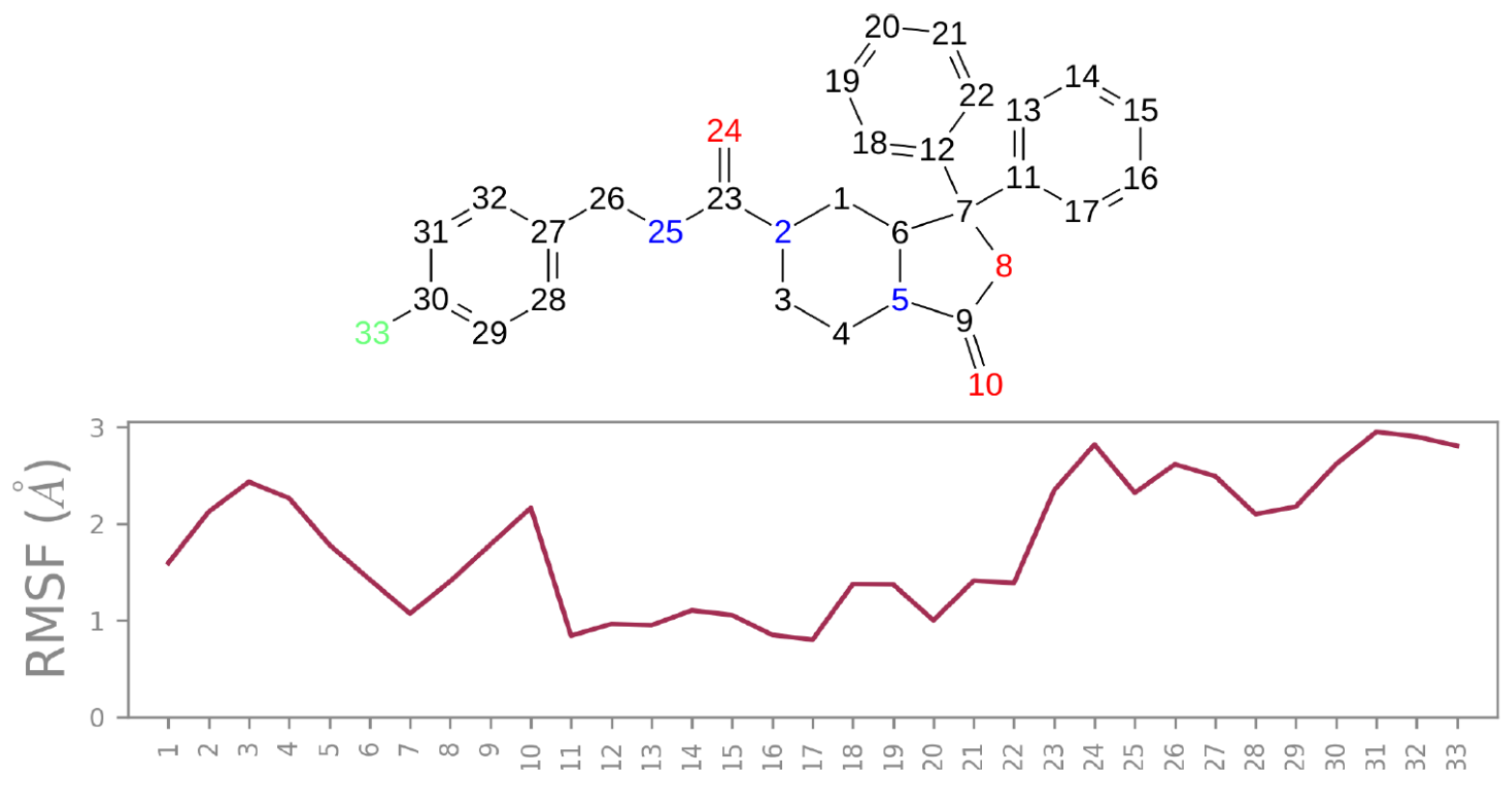

Figure S10. Ligand Root Mean Square Fluctuation (L-RMSF) of 1 in MD1 broken down by atom, corresponding to the $2 \mathrm{D}$ structure in the top panel.
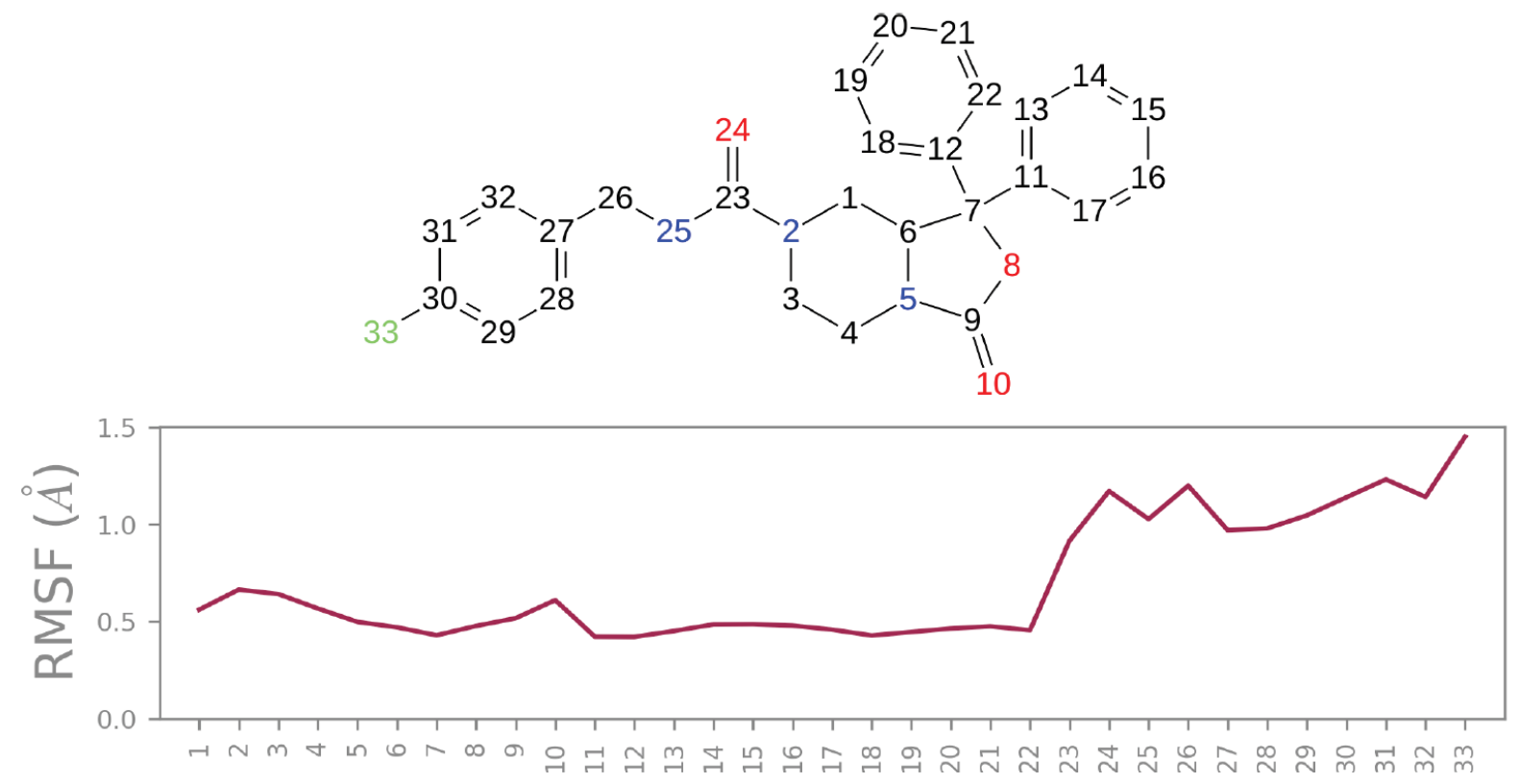

Figure S11. Ligand Root Mean Square Fluctuation (L-RMSF) of 1 in MD2 broken down by atom, corresponding to the $2 \mathrm{D}$ structure in the top panel. 

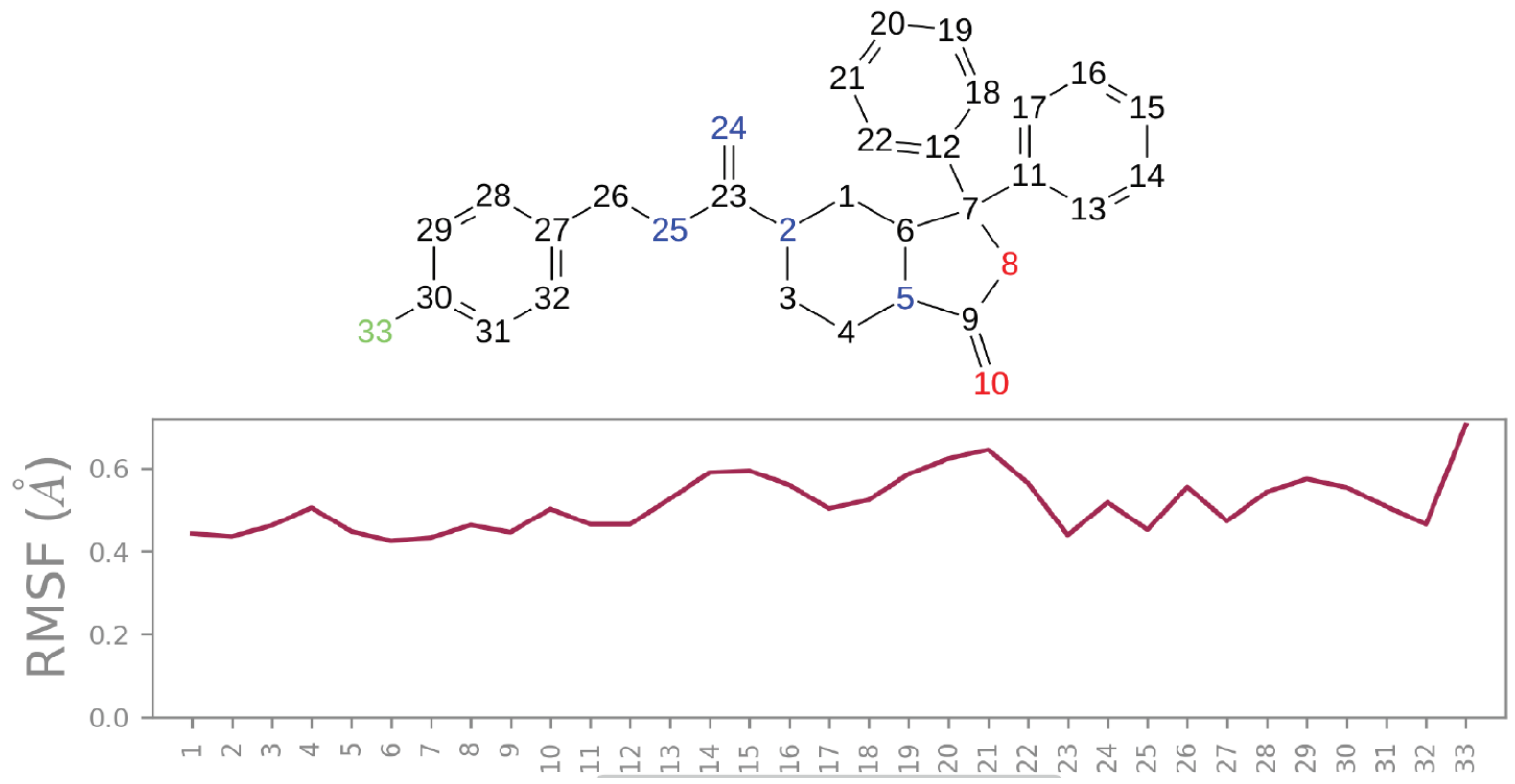

Figure S12. Ligand Root Mean Square Fluctuation (L-RMSF) of 16 in MD1 broken down by atom, corresponding to the $2 \mathrm{D}$ structure in the top panel.
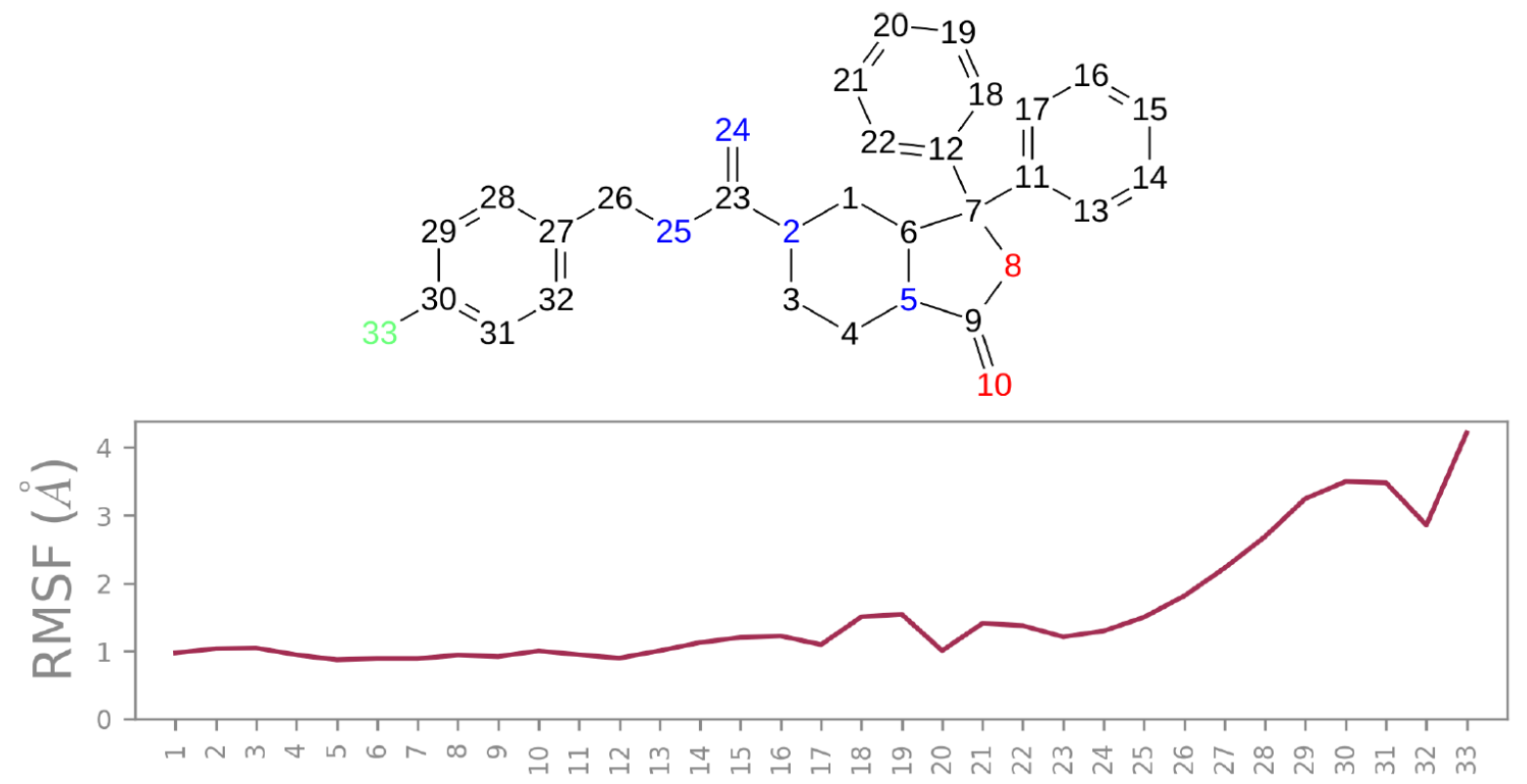

Figure S13. Ligand Root Mean Square Fluctuation (L-RMSF) of 16 in MD2 broken down by atom, corresponding to the $2 \mathrm{D}$ structure in the top panel. 

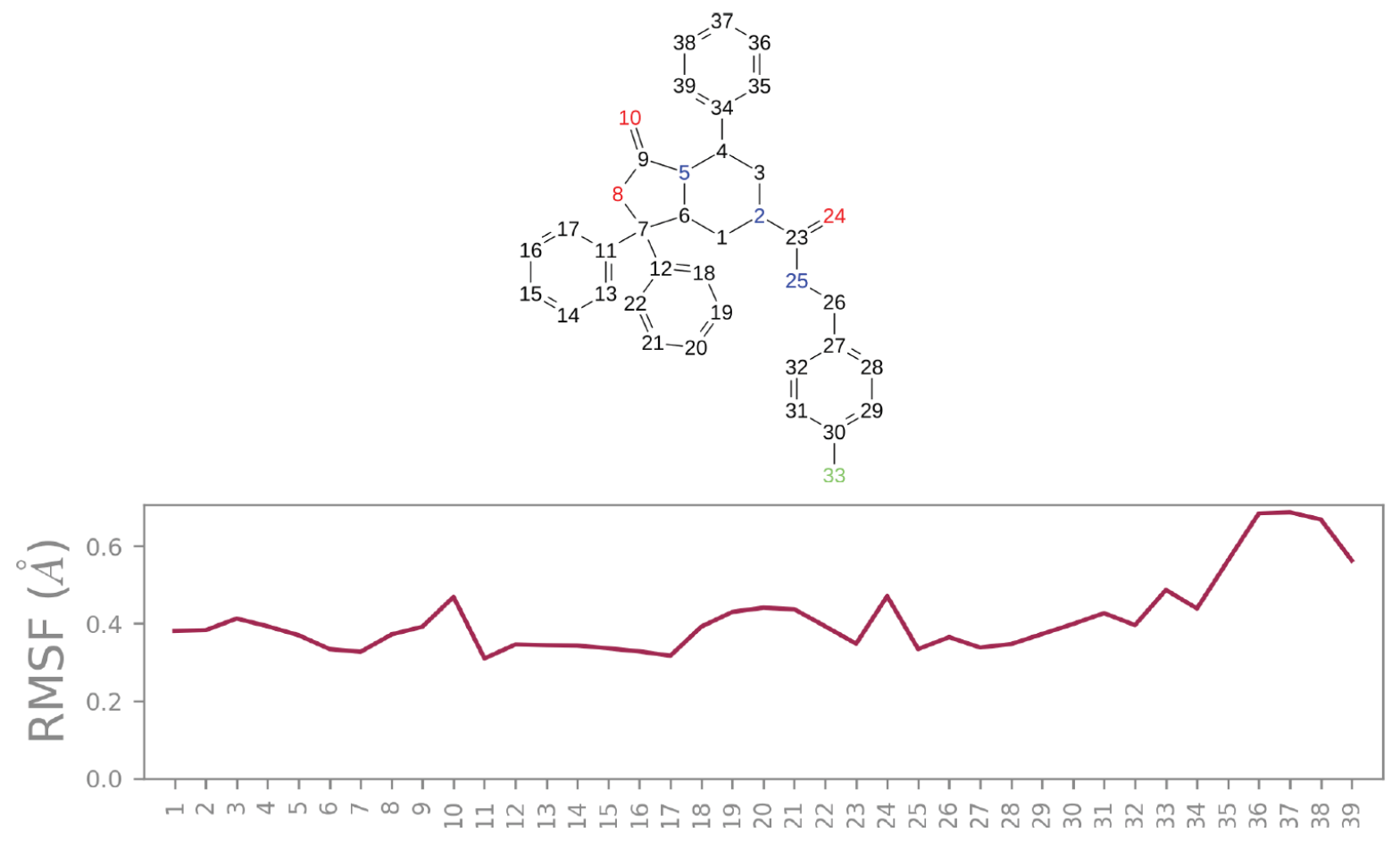

Figure S14. Ligand Root Mean Square Fluctuation (L-RMSF) of 21 in MD1 broken down by atom, corresponding to the $2 \mathrm{D}$ structure in the top panel.
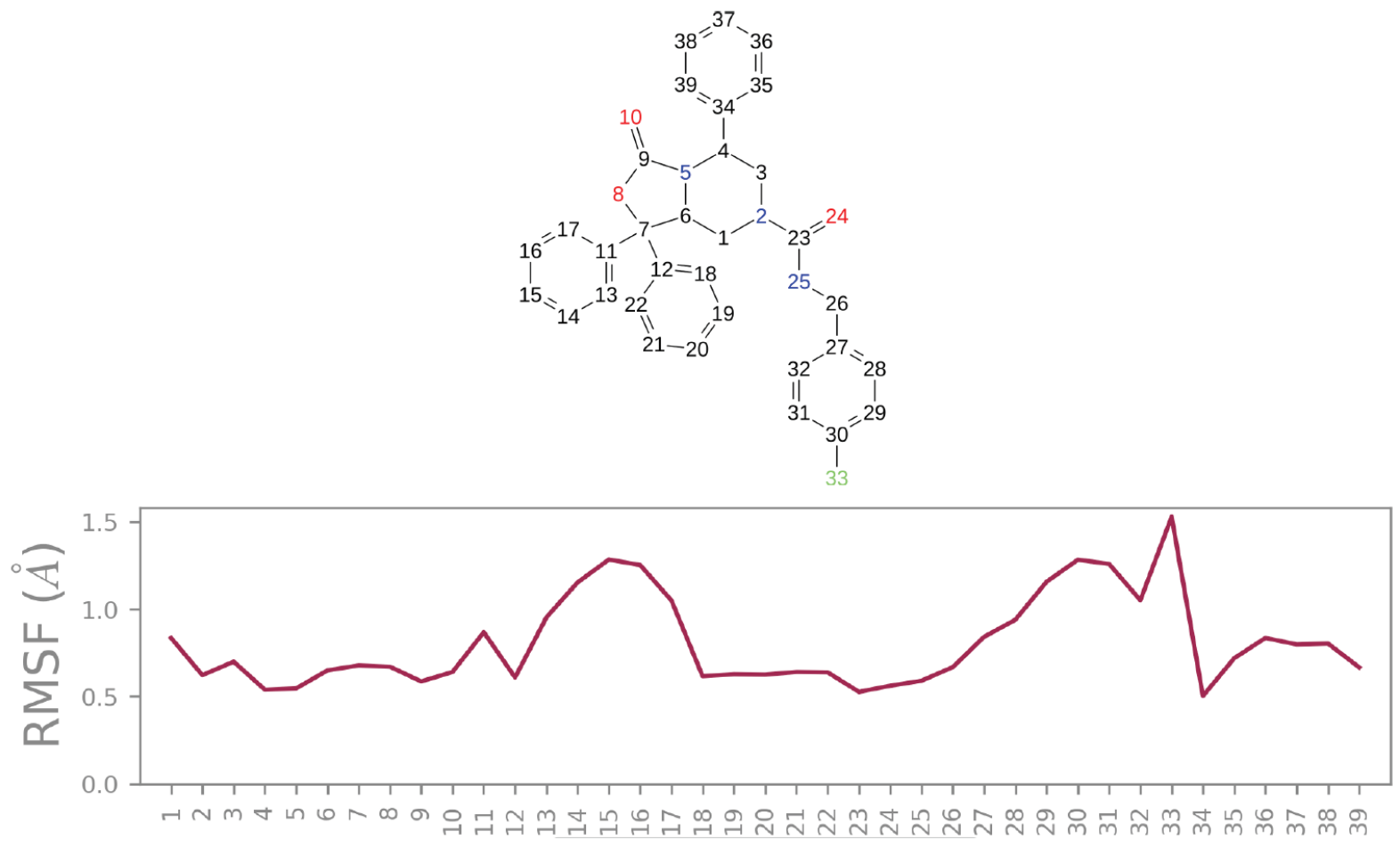

Figure S15. Ligand Root Mean Square Fluctuation (L-RMSF) of 21 in MD2 broken down by atom, corresponding to the $2 \mathrm{D}$ structure in the top panel. 


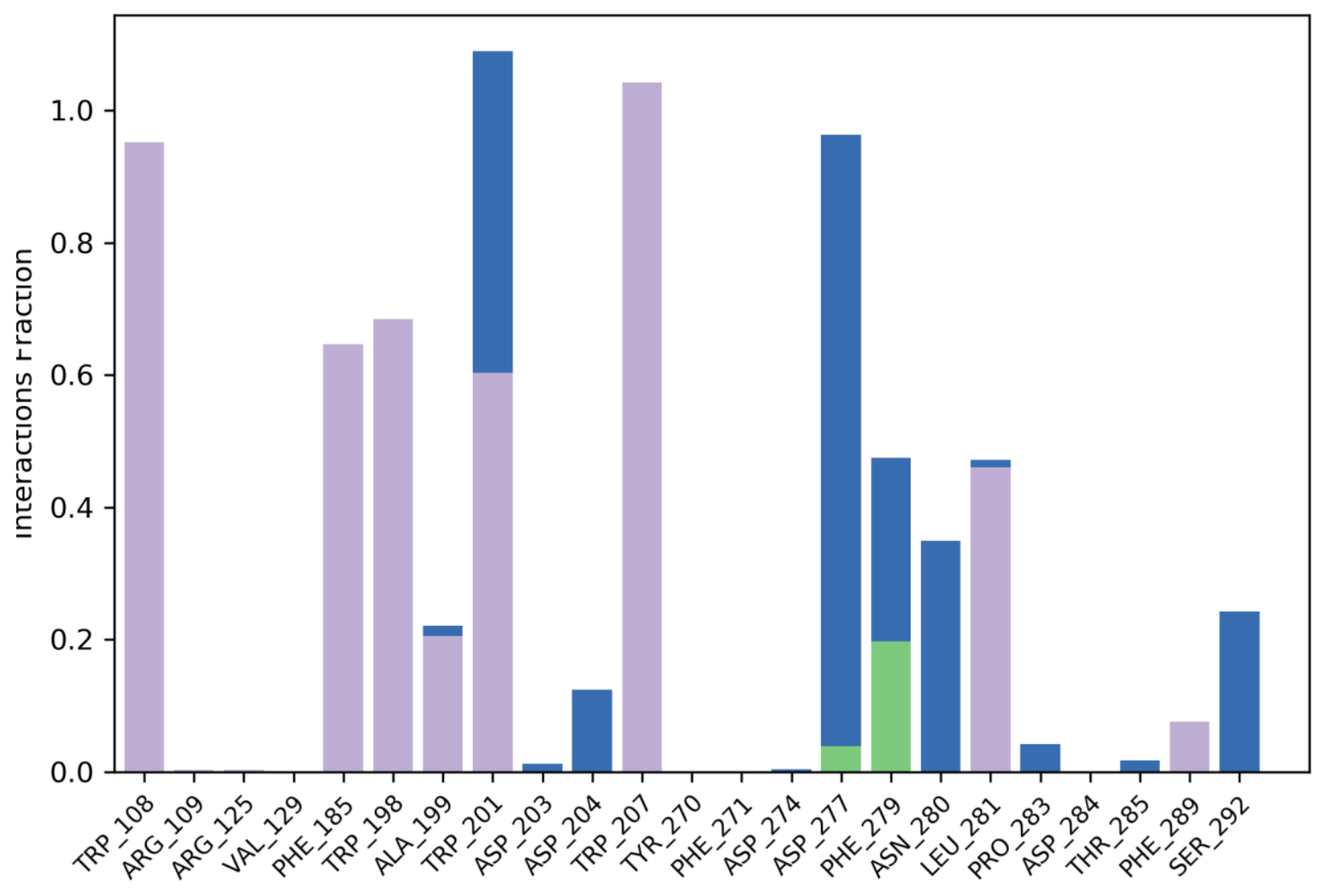

Figure S16. Plot of the ligand-protein interactions between 1 and NPSR in BM1. Protein-ligand interactions (or 'contacts') are categorized into four types: Hydrogen Bonds (green bars), Hydrophobic (violet bars), Ionic (magenta bars) and Water Bridges (blue bars). The stacked bar charts are normalized over the course of the trajectory: for example, a value of 0.7 suggests that $70 \%$ of the simulation time the specific interaction is maintained. Values over 1.0 are possible as some protein residue may make multiple contacts of same subtype with the ligand. 


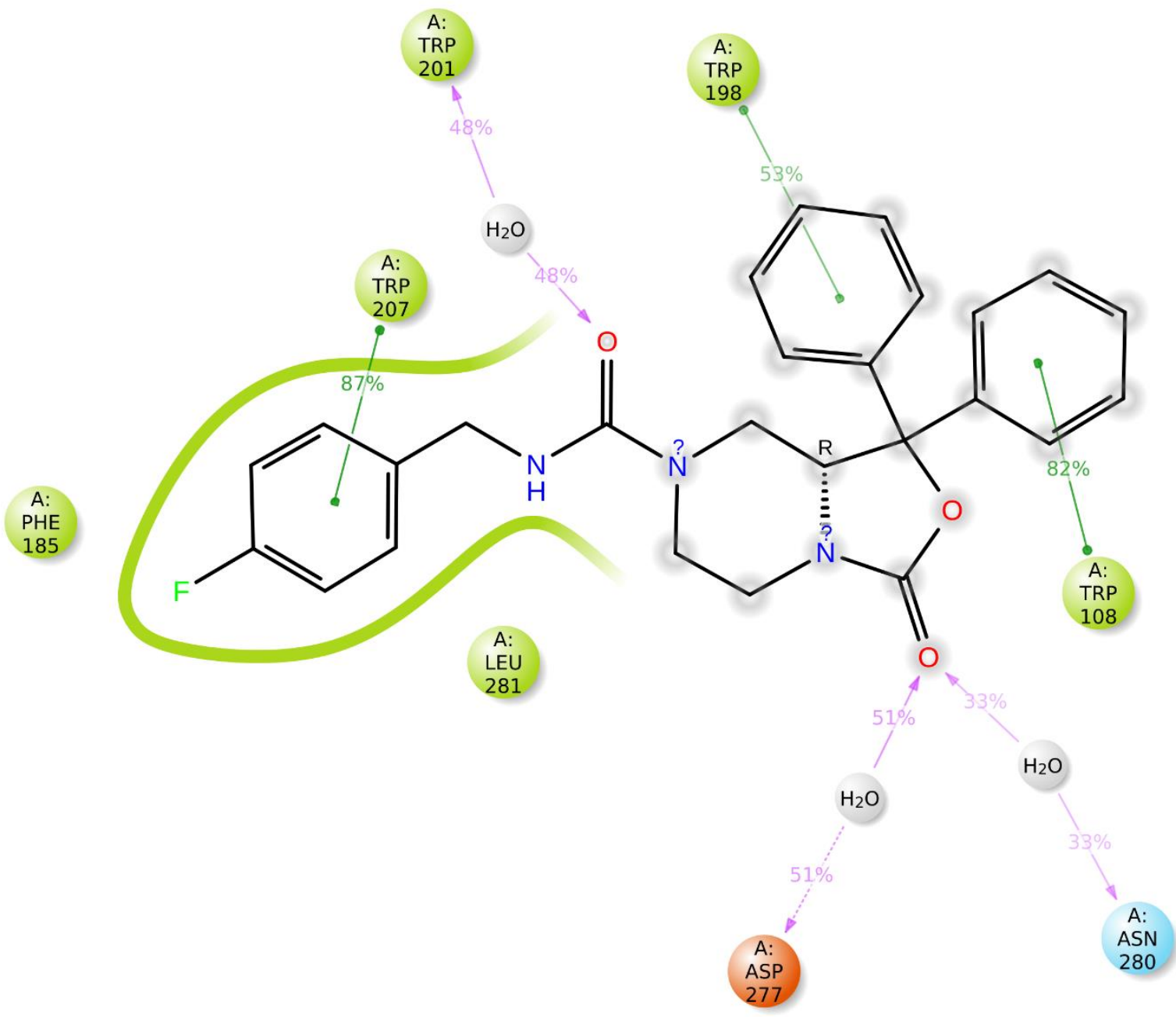

Figure S17. Schematic of detailed ligand atom interactions between 1 and NPSR during the MD simulation in BM1. Interactions that occur more than $30.0 \%$ of the simulation time in the selected trajectory (0.00 through $100.00 \mathrm{~ns})$, are shown. 


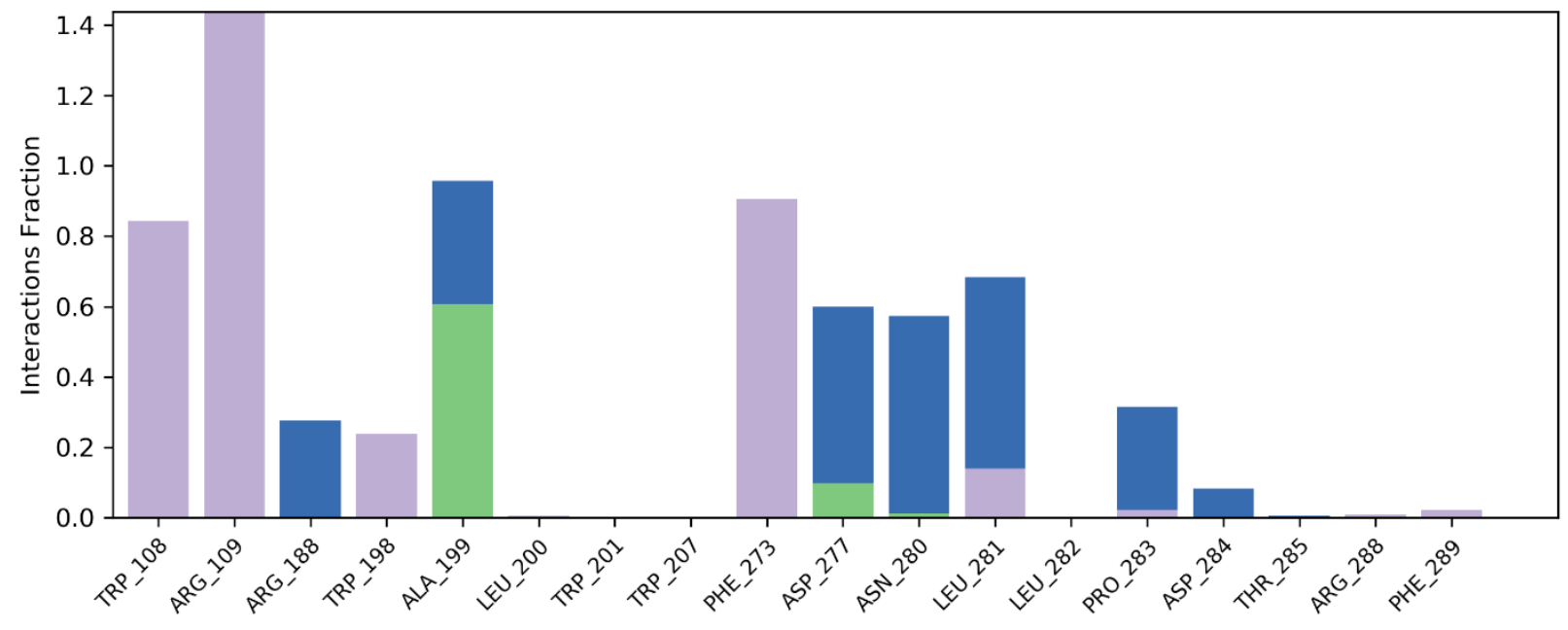

Figure S18. Plot of the ligand-protein interactions between 1 and NPSR in BM2 throughout the simulation. Protein-ligand interactions (or 'contacts') are categorized into four types: Hydrogen Bonds (green bars), Hydrophobic (violet bars), Ionic (magenta bars) and Water Bridges (blue bars). The stacked bar charts are normalized over the course of the trajectory: for example, a value of 0.7 suggests that $70 \%$ of the simulation time the specific interaction is maintained. Values over 1.0 are possible as some protein residue may make multiple contacts of same subtype with the ligand. 


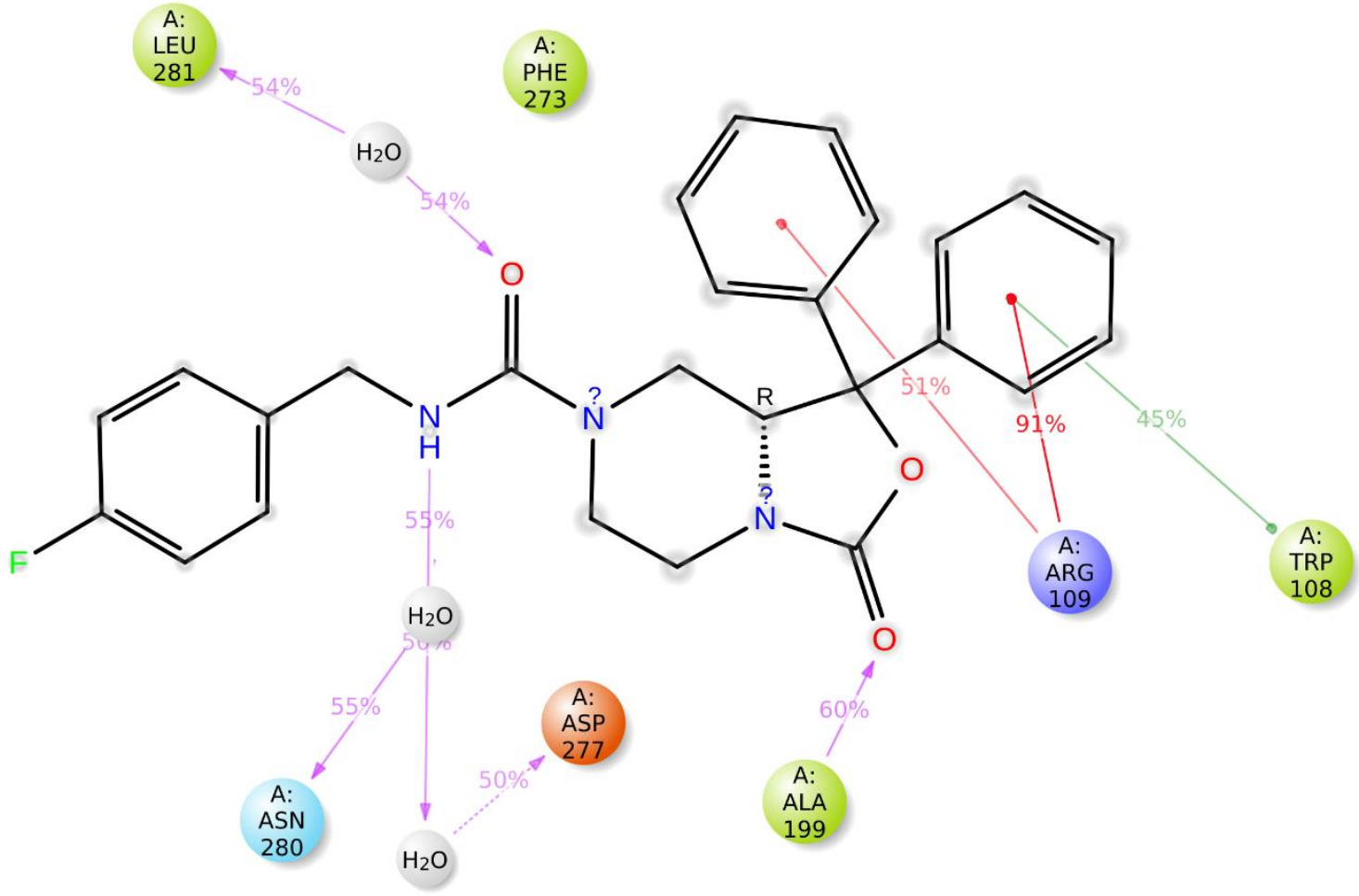

Figure S19. Schematic of detailed ligand atom interactions between 1 and NPSR during the MD simulation in BM2. Interactions that occur more than $30.0 \%$ of the simulation time in the selected trajectory (0.00 through $100.00 \mathrm{~ns})$, are shown. 


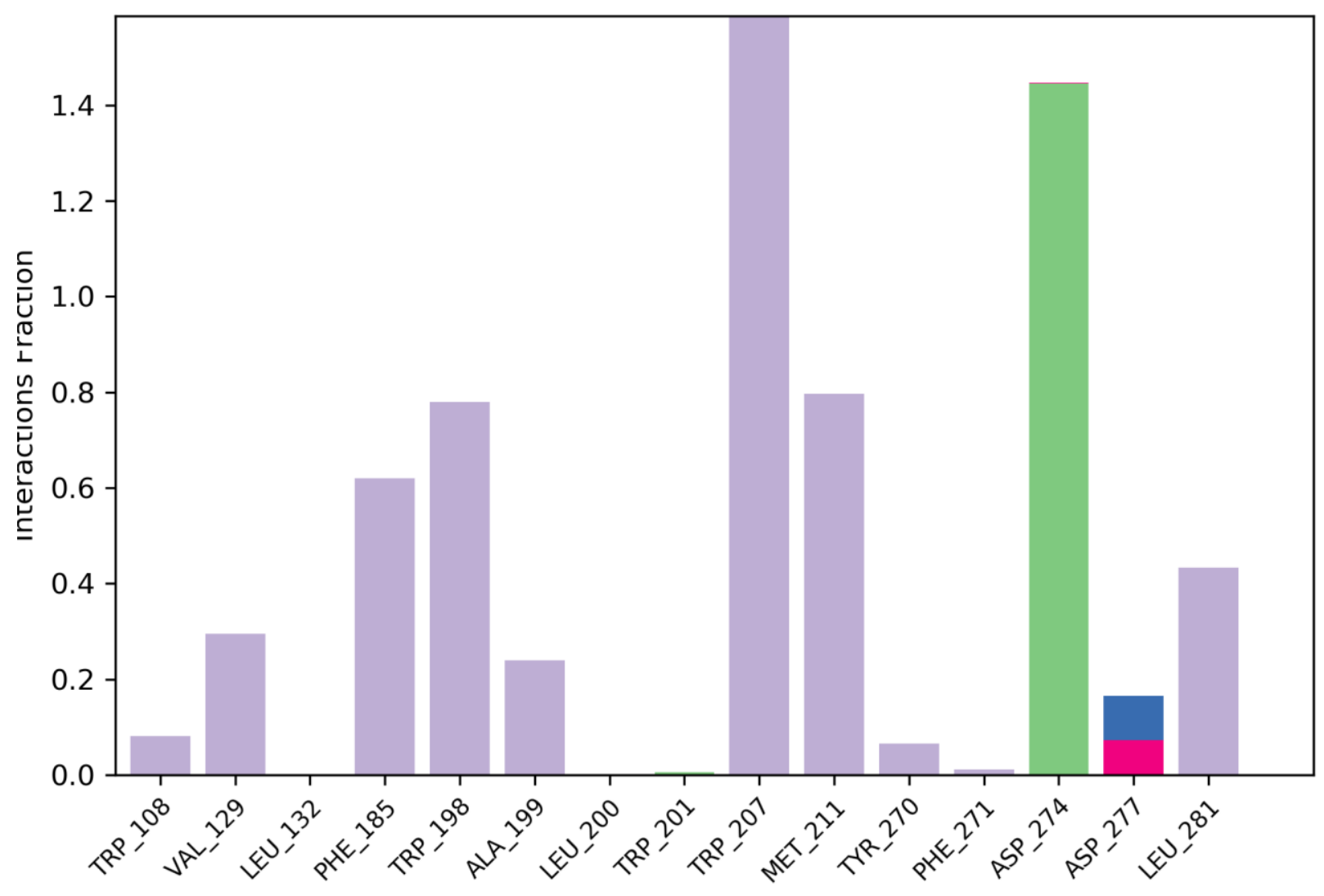

Figure S20. Plot of the ligand-protein interactions between 16 and NPSR in BM1 throughout the simulation. Protein-ligand interactions (or 'contacts') are categorized into four types: Hydrogen Bonds (green bars), Hydrophobic (violet bars), Ionic (magenta bars) and Water Bridges (blue bars). The stacked bar charts are normalized over the course of the trajectory: for example, a value of 0.7 suggests that $70 \%$ of the simulation time the specific interaction is maintained. Values over 1.0 are possible as some protein residue may make multiple contacts of same subtype with the ligand. 


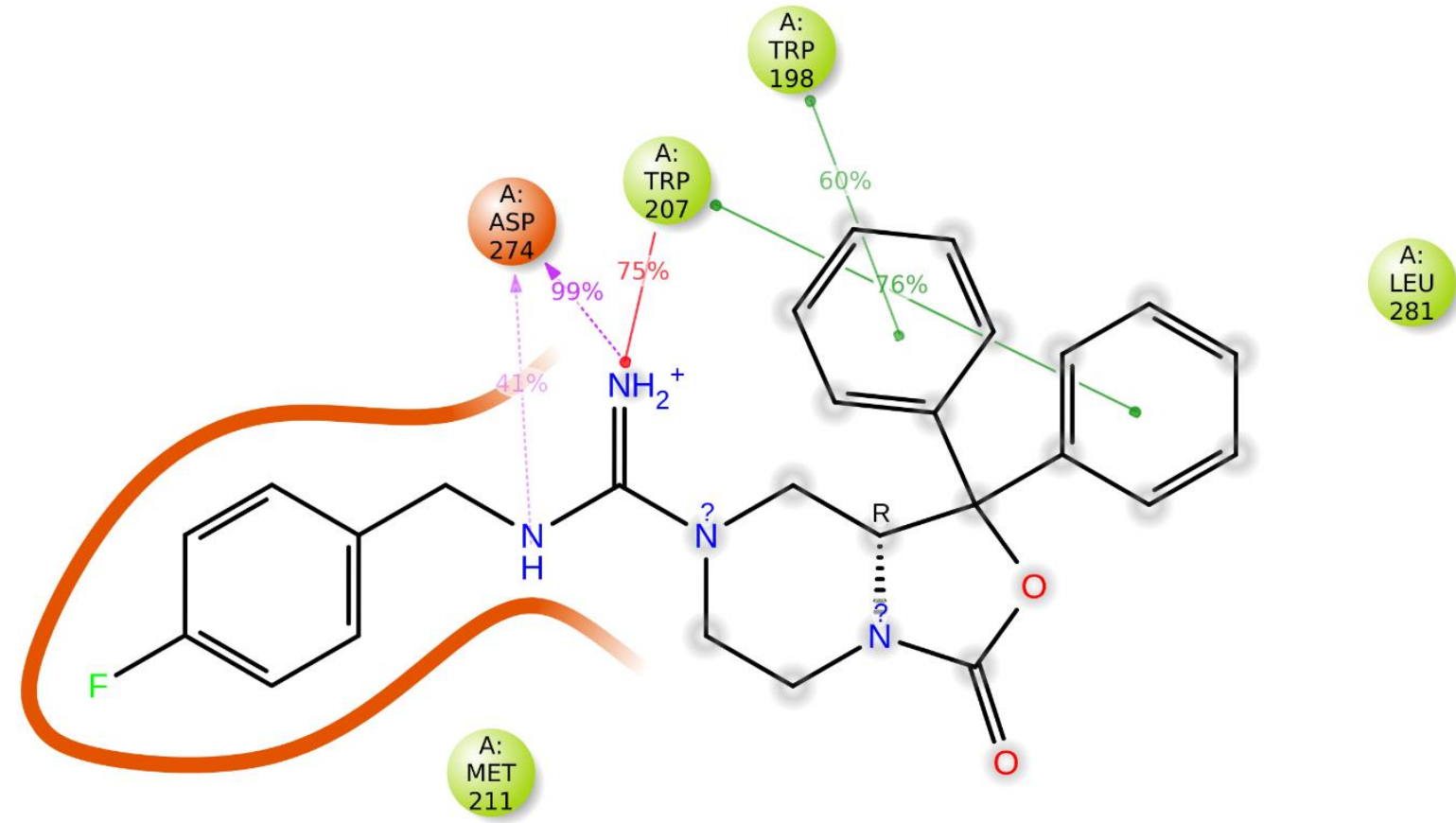

$$
\begin{aligned}
& \text { A: } \\
& \text { PHE } \\
& 185
\end{aligned}
$$

Figure S21. Schematic of detailed ligand atom interactions between 16 and NPSR during the MD simulation in BM1. Interactions that occur more than $30.0 \%$ of the simulation time in the selected trajectory (0.00 through $100.00 \mathrm{~ns})$, are shown. 


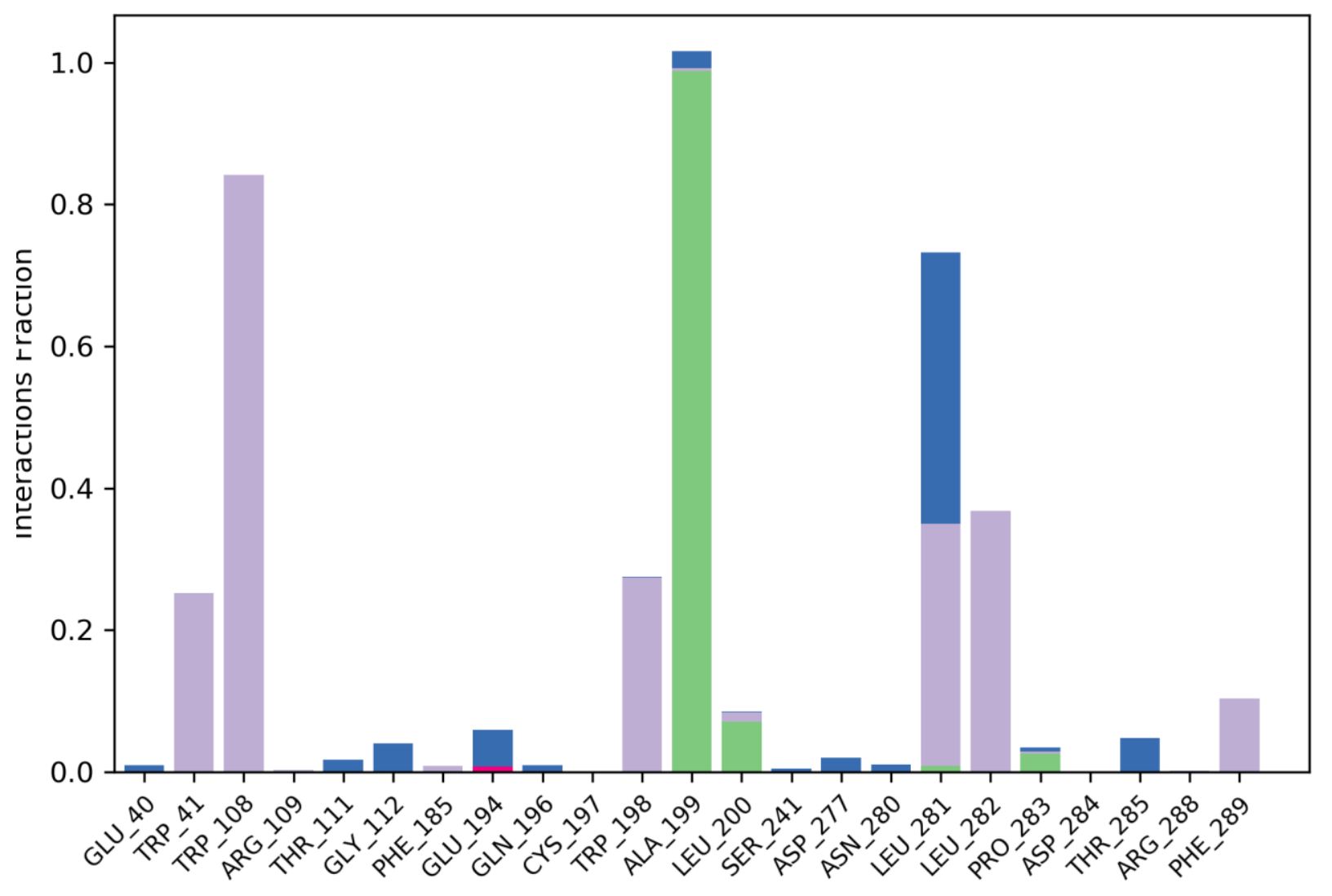

Figure S22. Plot of the ligand-protein interactions between 16 and NPSR in BM2 throughout the simulation. Protein-ligand interactions (or 'contacts') are categorized into four types: Hydrogen Bonds (green bars), Hydrophobic (violet bars), Ionic (magenta bars) and Water Bridges (blue bars). The stacked bar charts are normalized over the course of the trajectory: for example, a value of 0.7 suggests that $70 \%$ of the simulation time the specific interaction is maintained. Values over 1.0 are possible as some protein residue may make multiple contacts of same subtype with the ligand. 


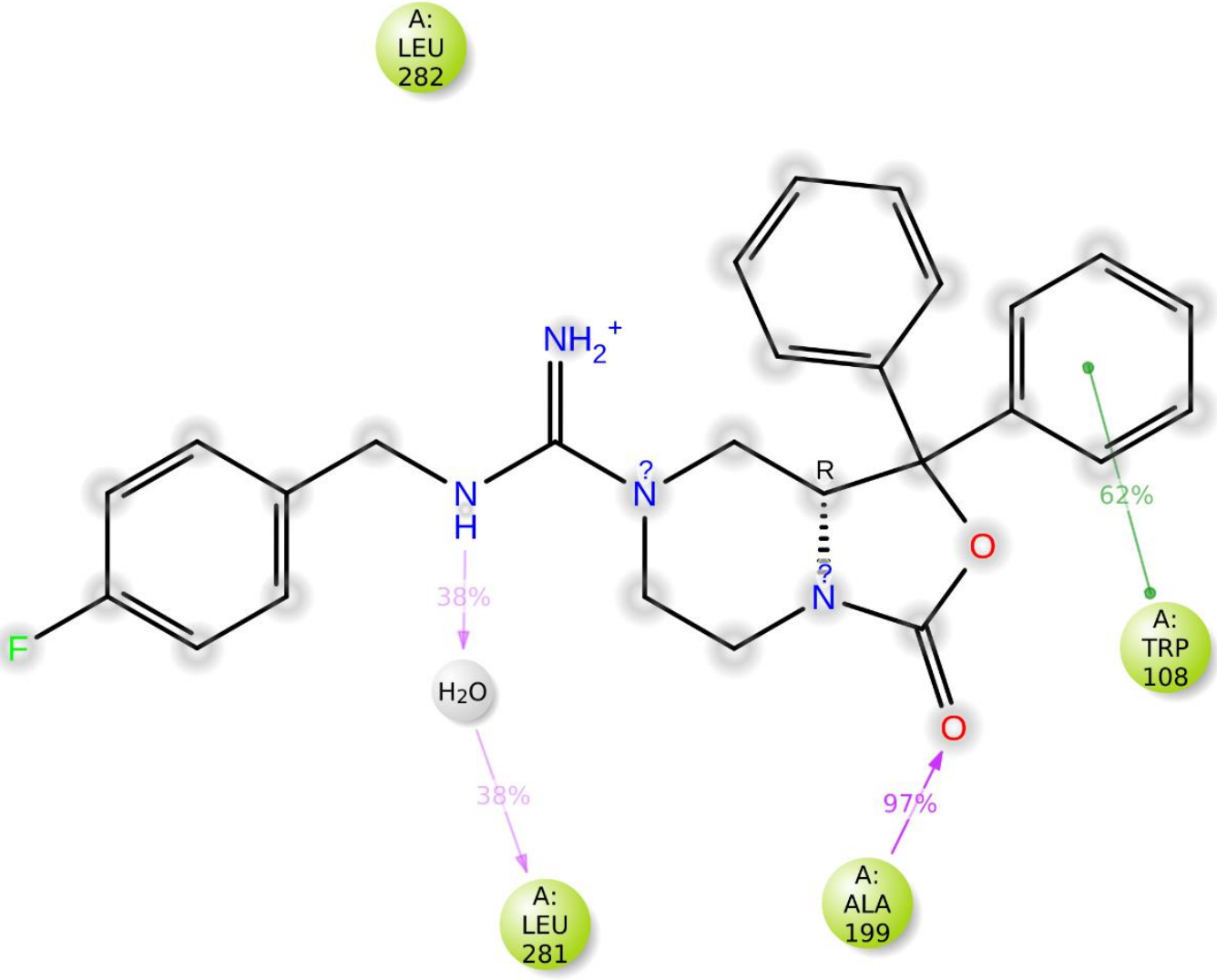

Figure S23. Schematic of detailed ligand atom interactions between $\mathbf{1 6}$ and NPSR during the MD simulation in BM2. Interactions that occur more than $30.0 \%$ of the simulation time in the selected trajectory (0.00 through $100.00 \mathrm{~ns})$, are shown. 


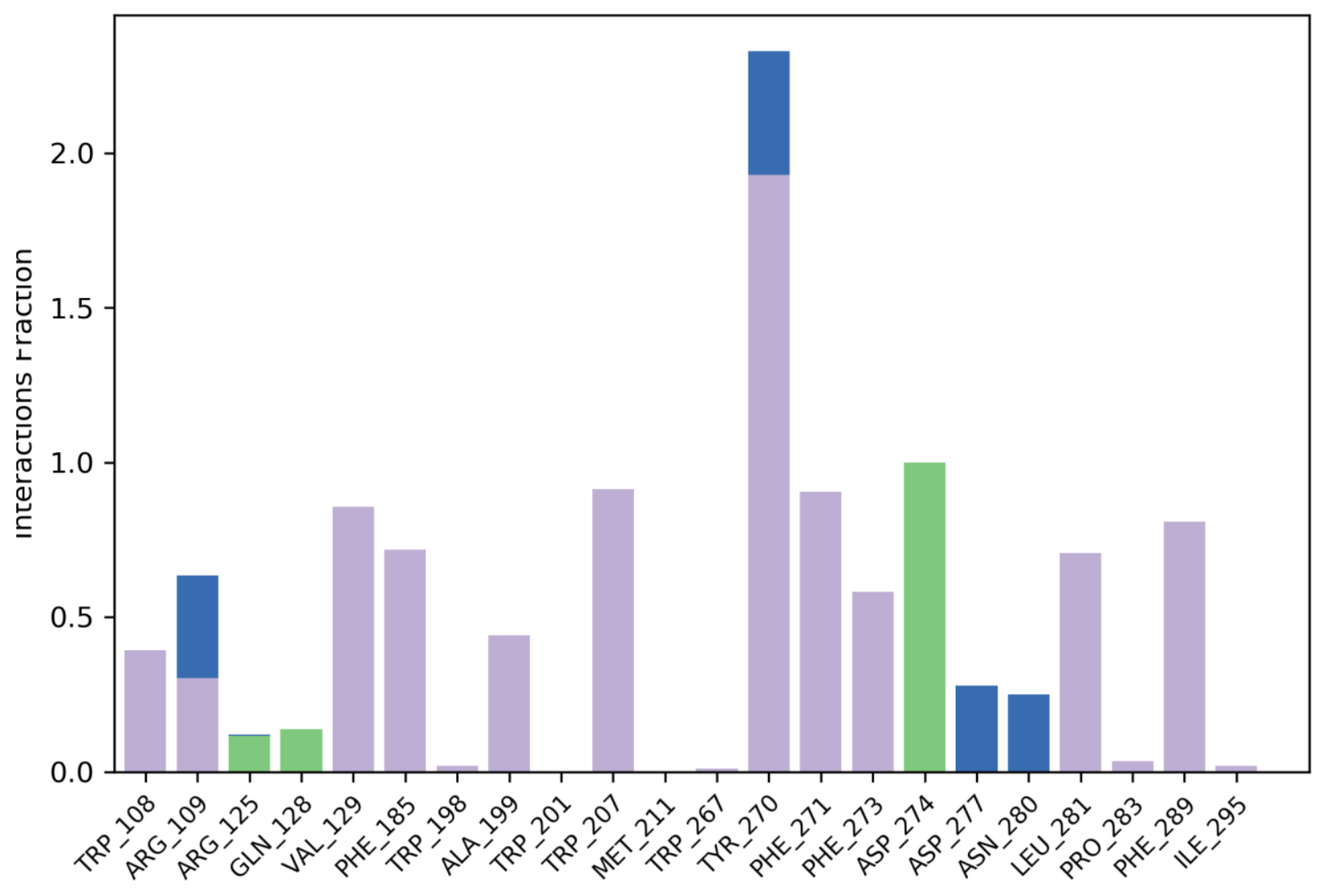

Figure S24. Plot of the ligand-protein interactions between 21 and NPSR in BM1 throughout the simulation. Protein-ligand interactions (or 'contacts') are categorized into four types: Hydrogen Bonds (green bars), Hydrophobic (violet bars), Ionic (magenta bars) and Water Bridges (blue bars). The stacked bar charts are normalized over the course of the trajectory: for example, a value of 0.7 suggests that $70 \%$ of the simulation time the specific interaction is maintained. Values over 1.0 are possible as some protein residue may make multiple contacts of same subtype with the ligand. 


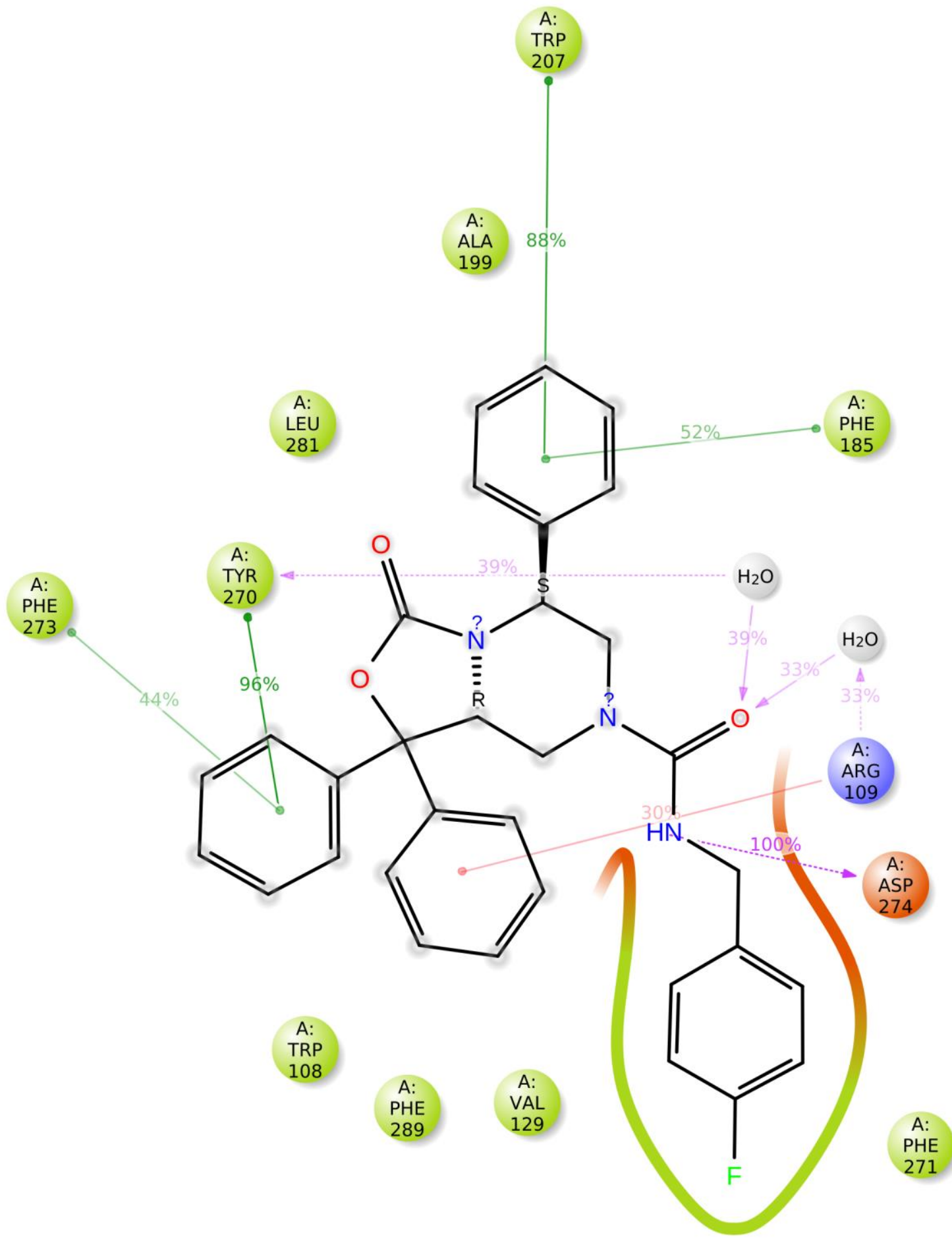

Figure S25. Schematic of detailed ligand atom interactions between 21 and NPSR during the MD simulation in BM1. Interactions that occur more than $30.0 \%$ of the simulation time in the selected trajectory (0.00 through $100.00 \mathrm{~ns})$, are shown. 


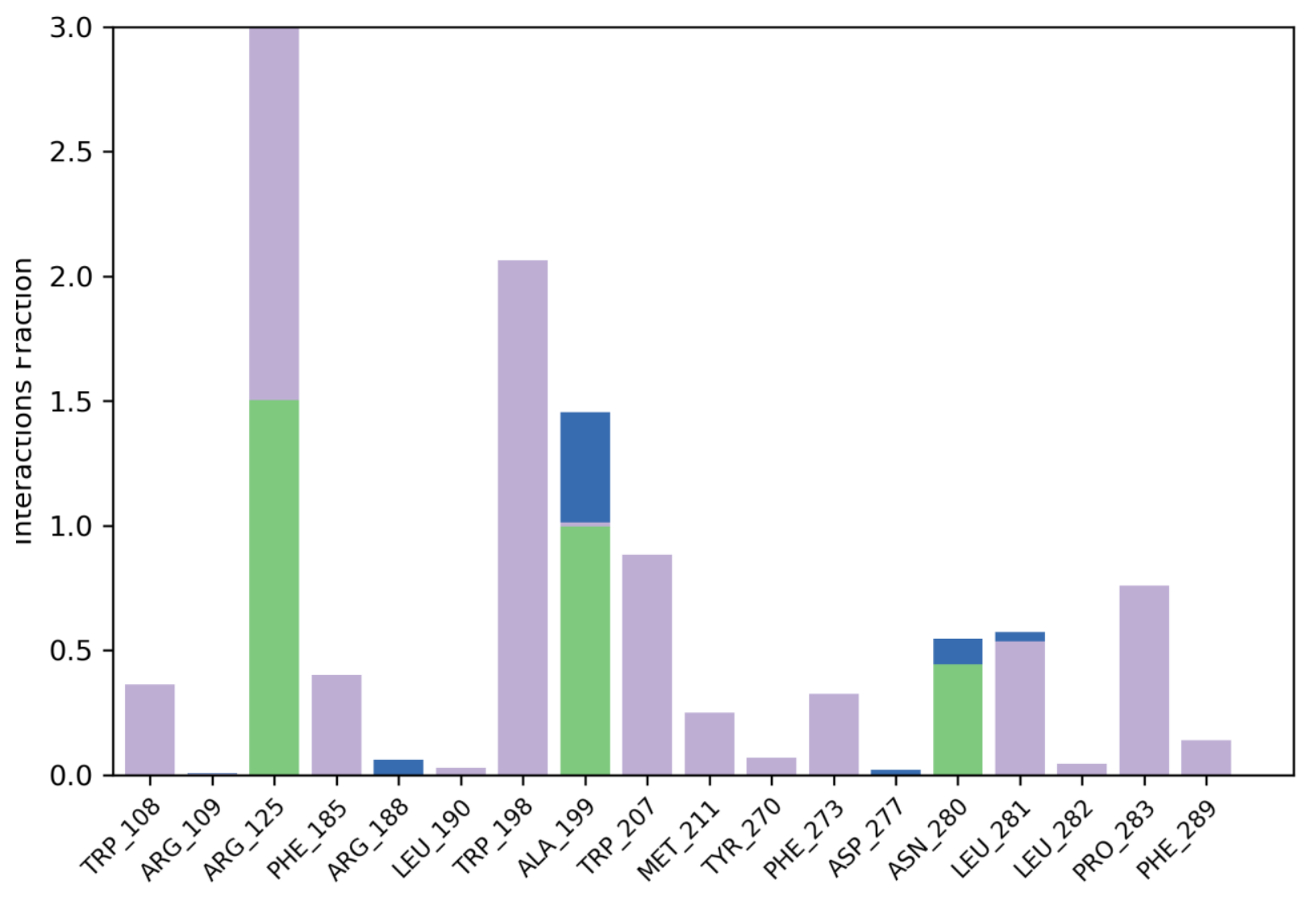

Figure S26. Plot of the ligand-protein interactions between 21 and NPSR in BM2 throughout the simulation. Protein-ligand interactions (or 'contacts') are categorized into four types: Hydrogen Bonds (green bars), Hydrophobic (violet bars), Ionic (magenta bars) and Water Bridges (blue bars). The stacked bar charts are normalized over the course of the trajectory: for example, a value of 0.7 suggests that $70 \%$ of the simulation time the specific interaction is maintained. Values over 1.0 are possible as some protein residue may make multiple contacts of same subtype with the ligand. 


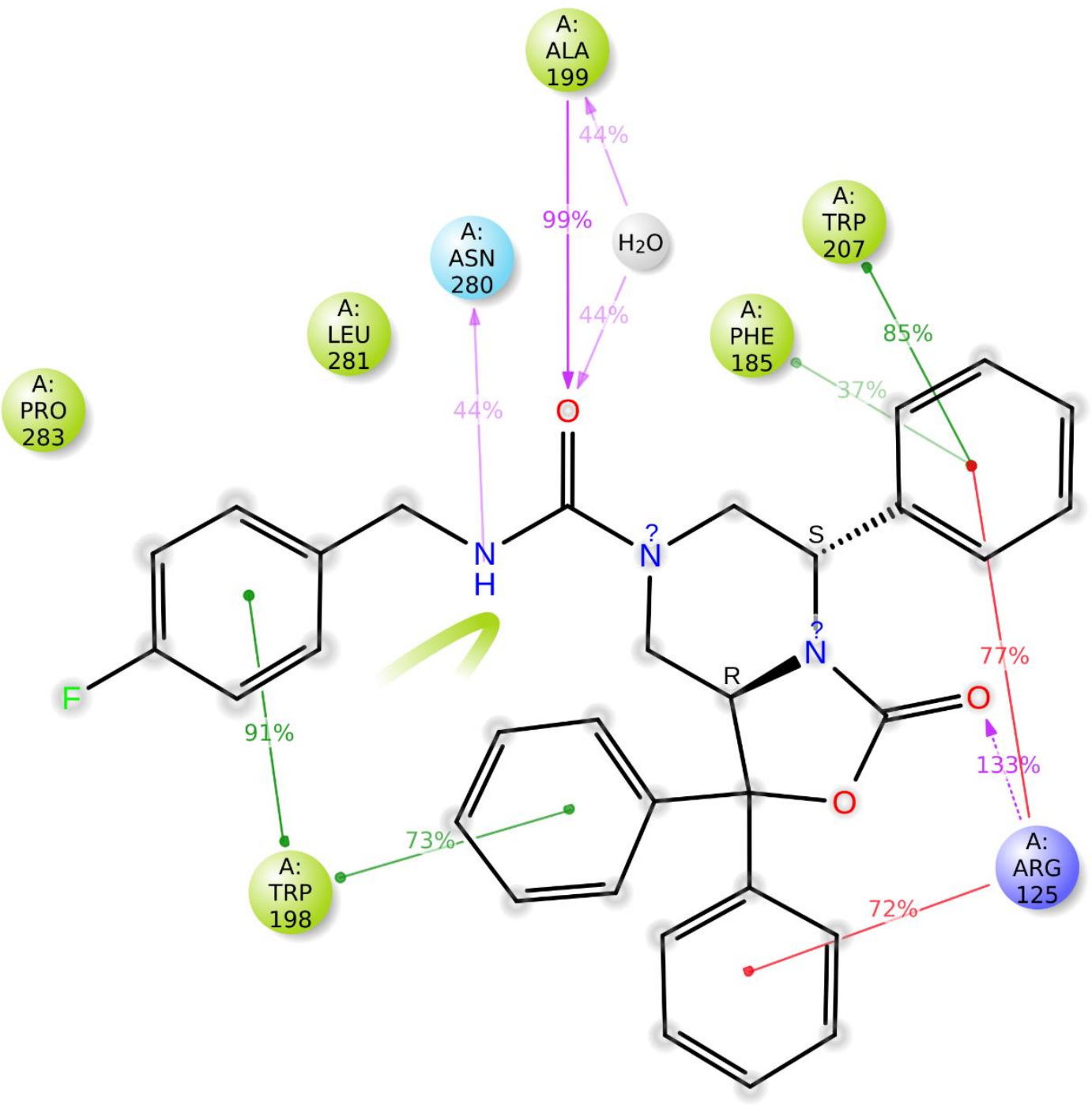

Figure S27. Schematic of detailed ligand atom interactions between 21 and NPSR during the MD simulation in BM2. Interactions that occur more than $30.0 \%$ of the simulation time in the selected trajectory (0.00 through $100.00 \mathrm{~ns})$, are shown. 


\section{Compound 3}

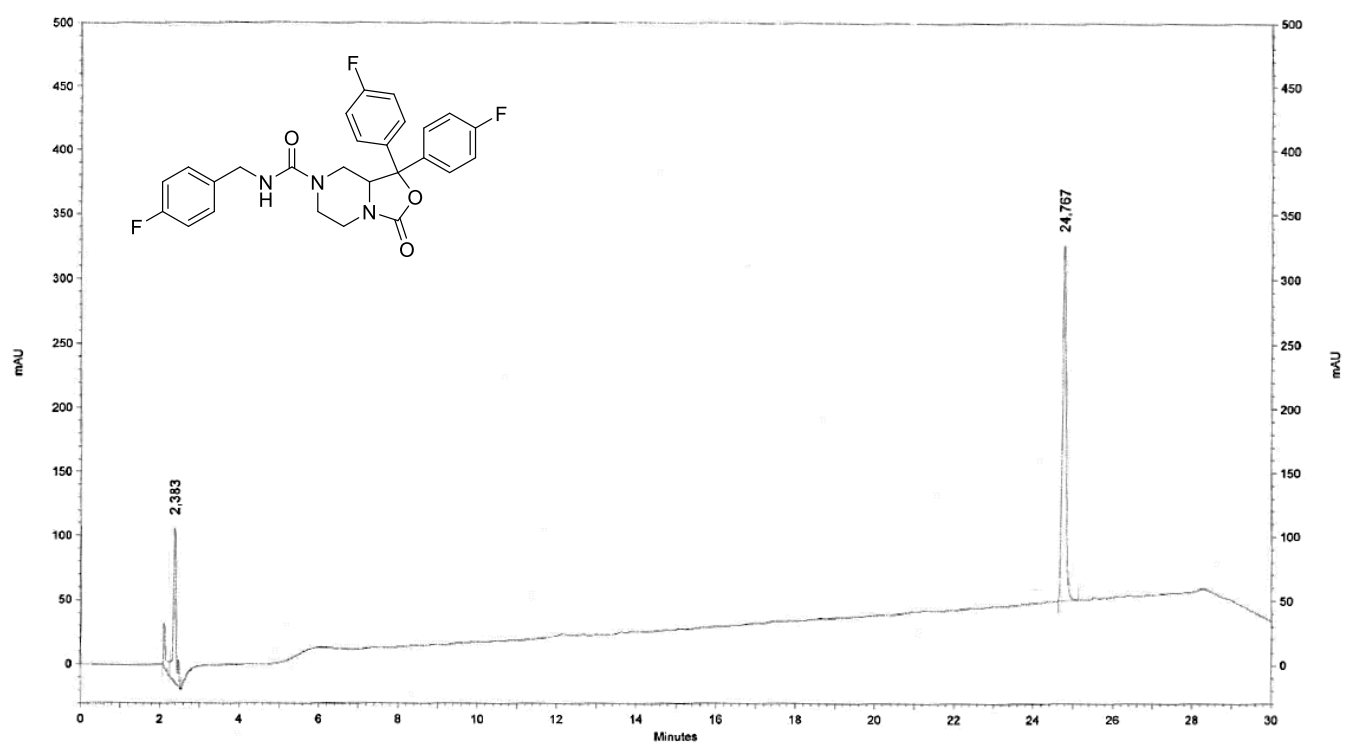

\section{Compound 4}

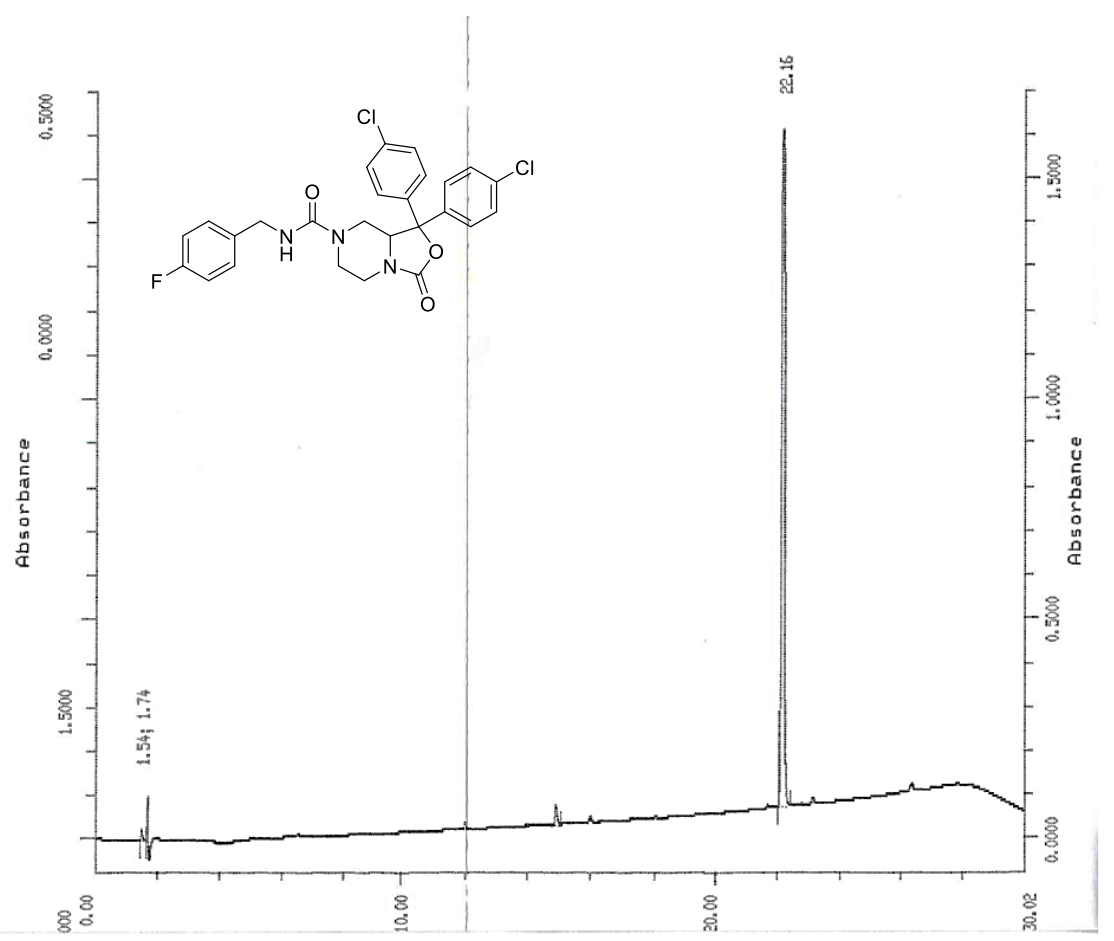




\section{Compound 5}

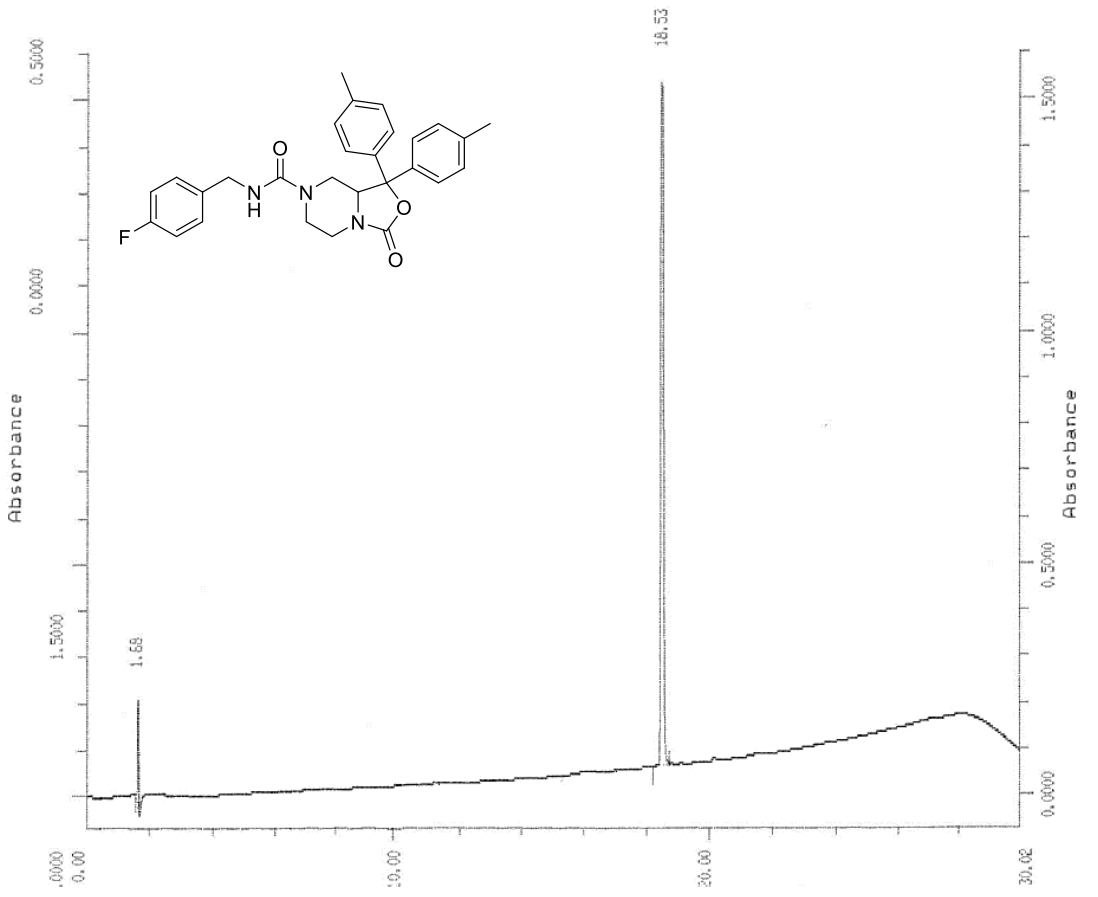

Compound 6

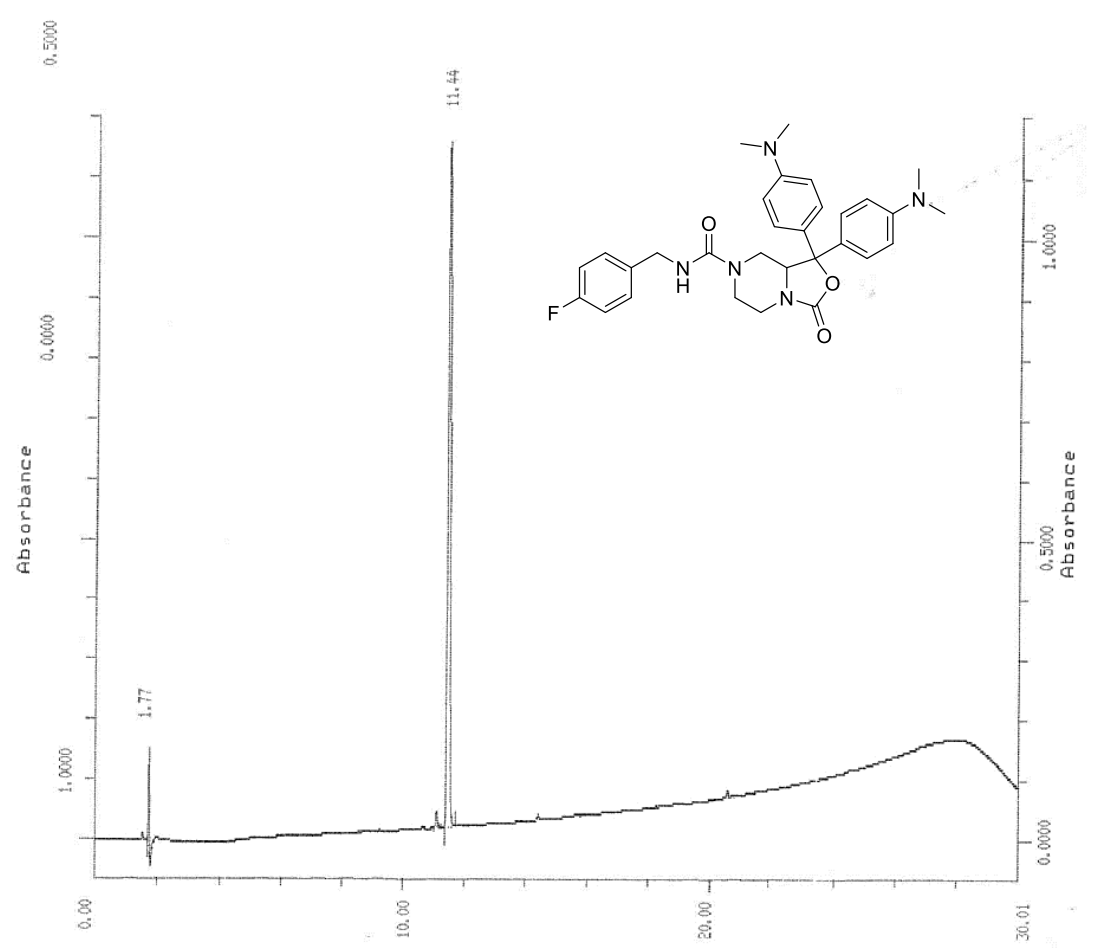




\section{Compound 7}

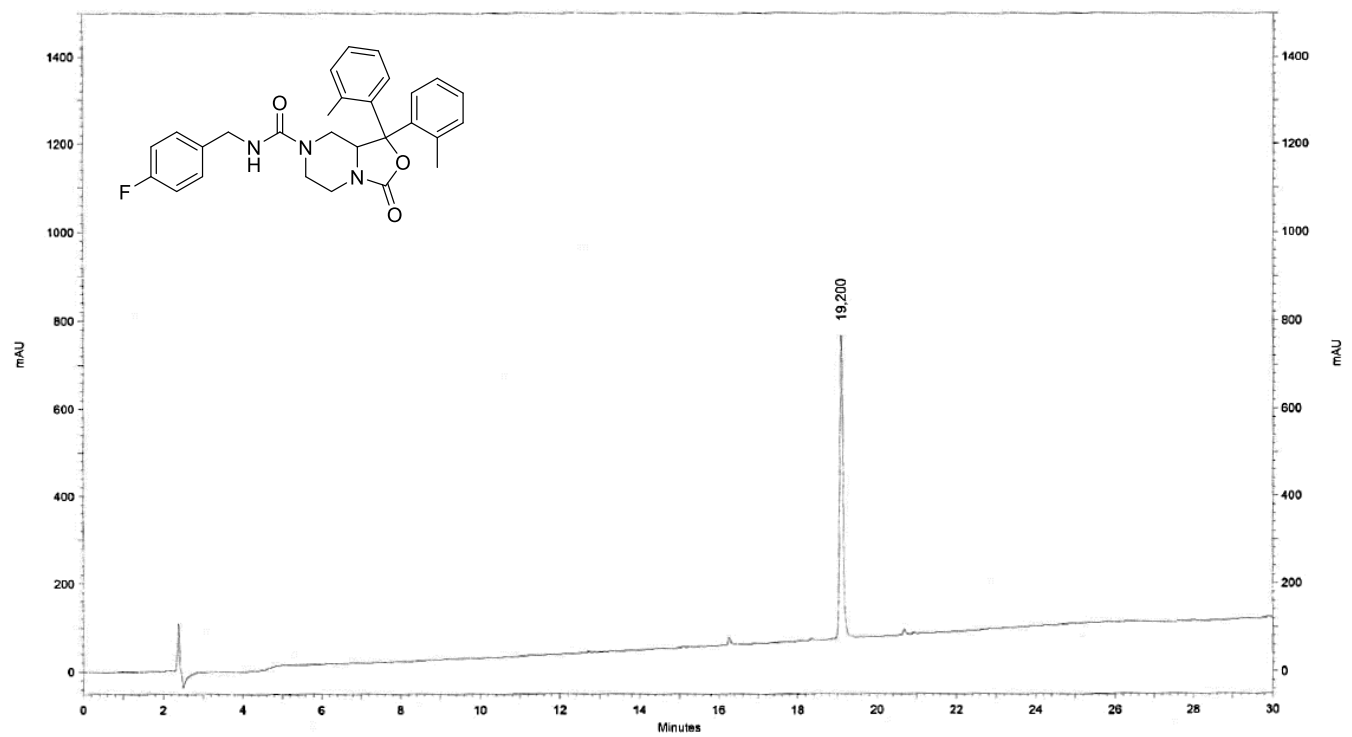

\section{Compound 8}

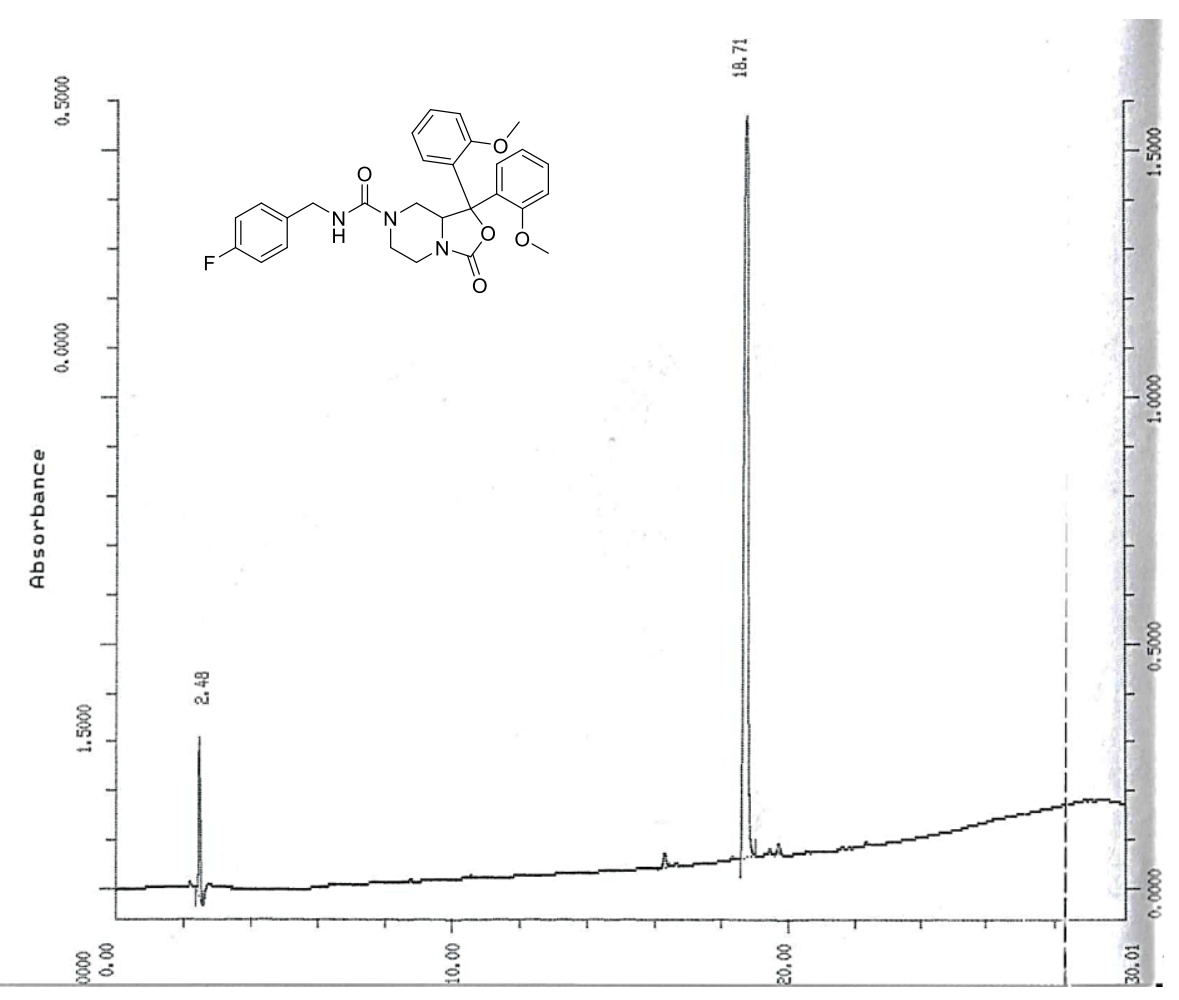




\section{Compound 9}

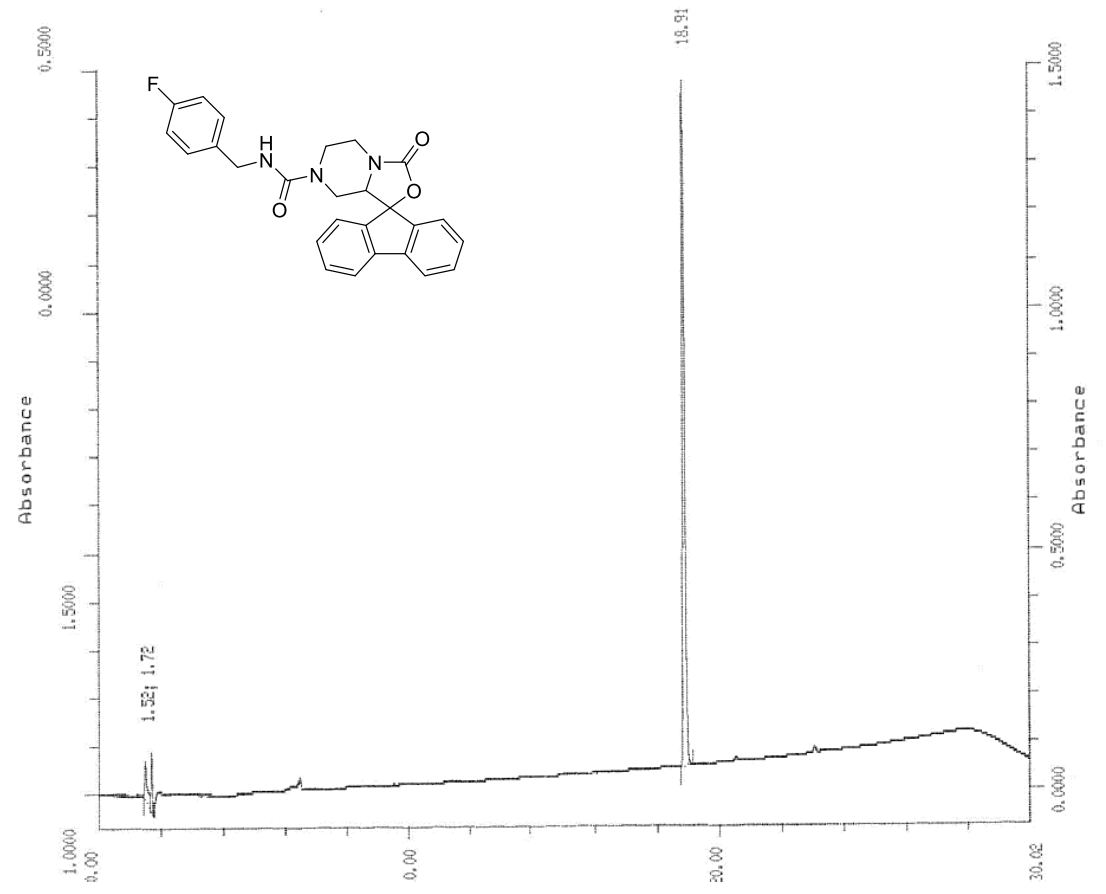

\section{Compound 10}

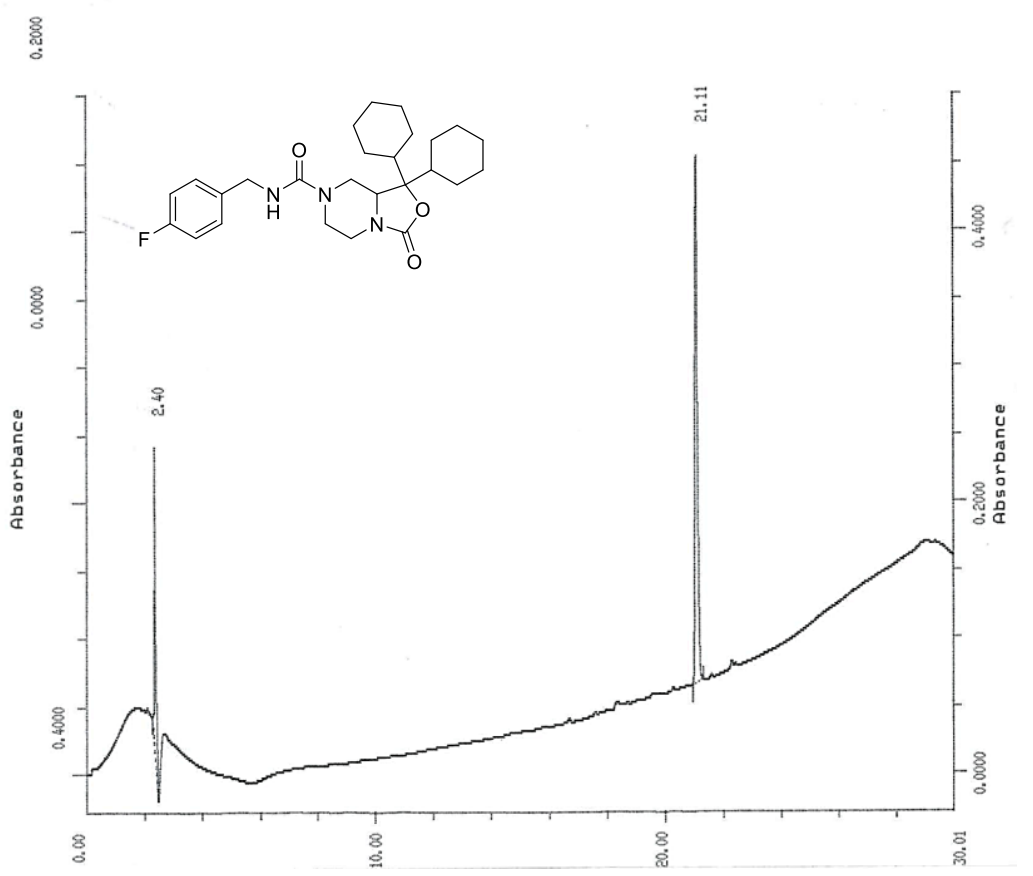




\section{Compound 11}

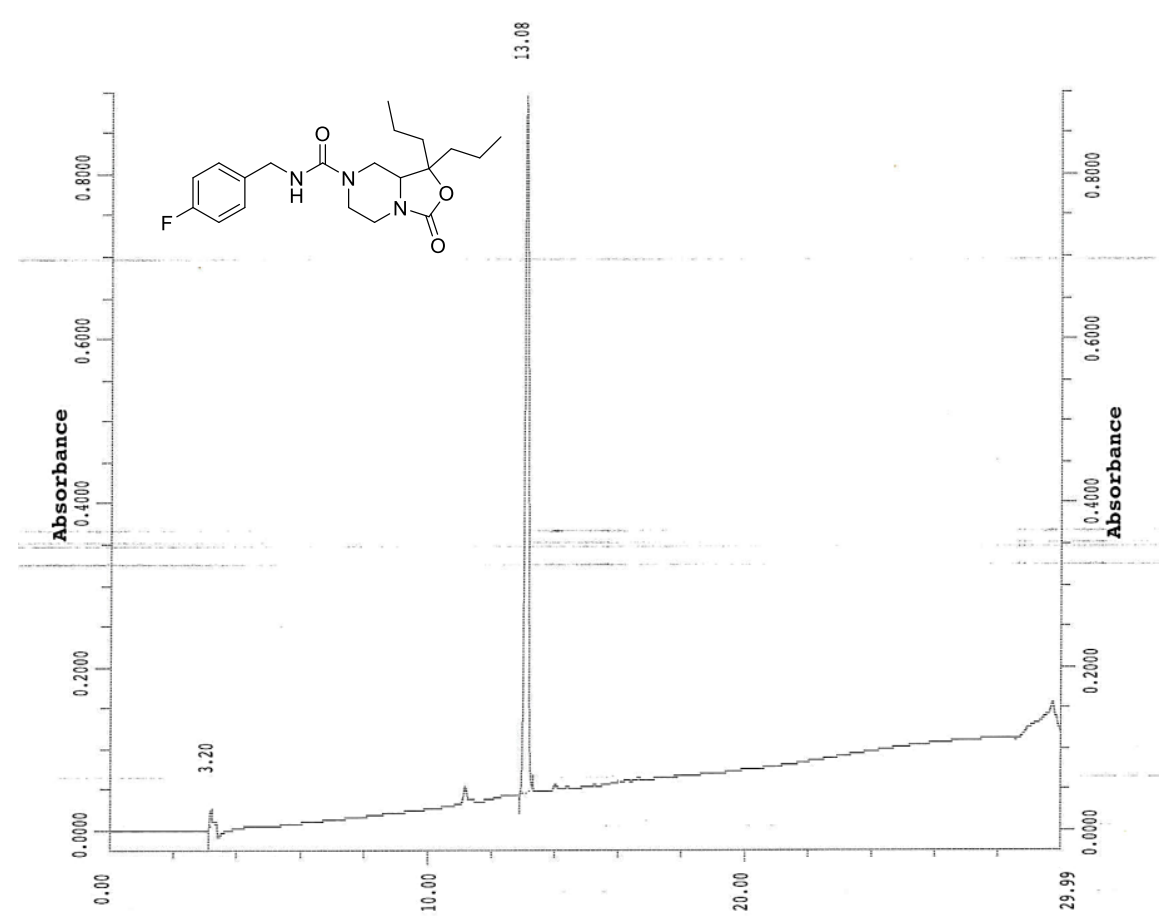

\section{Compound 12}

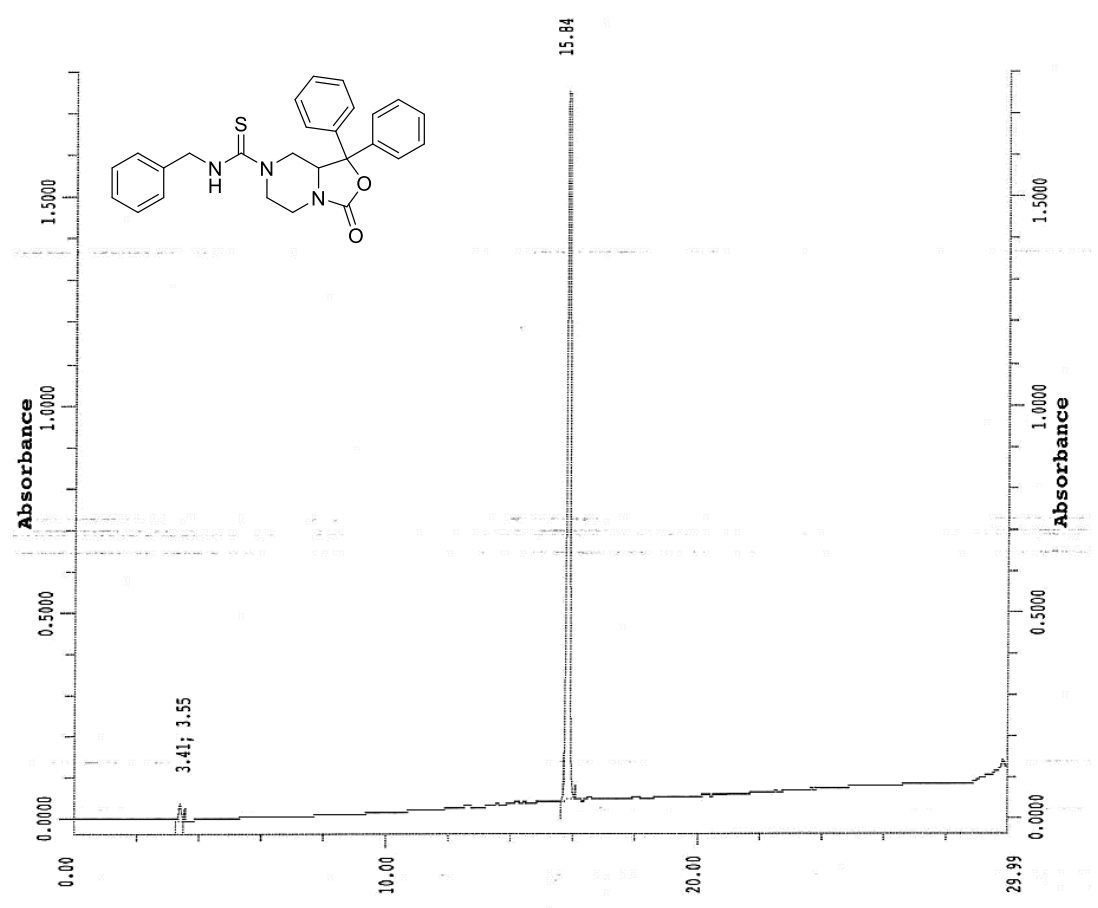


Compound 13

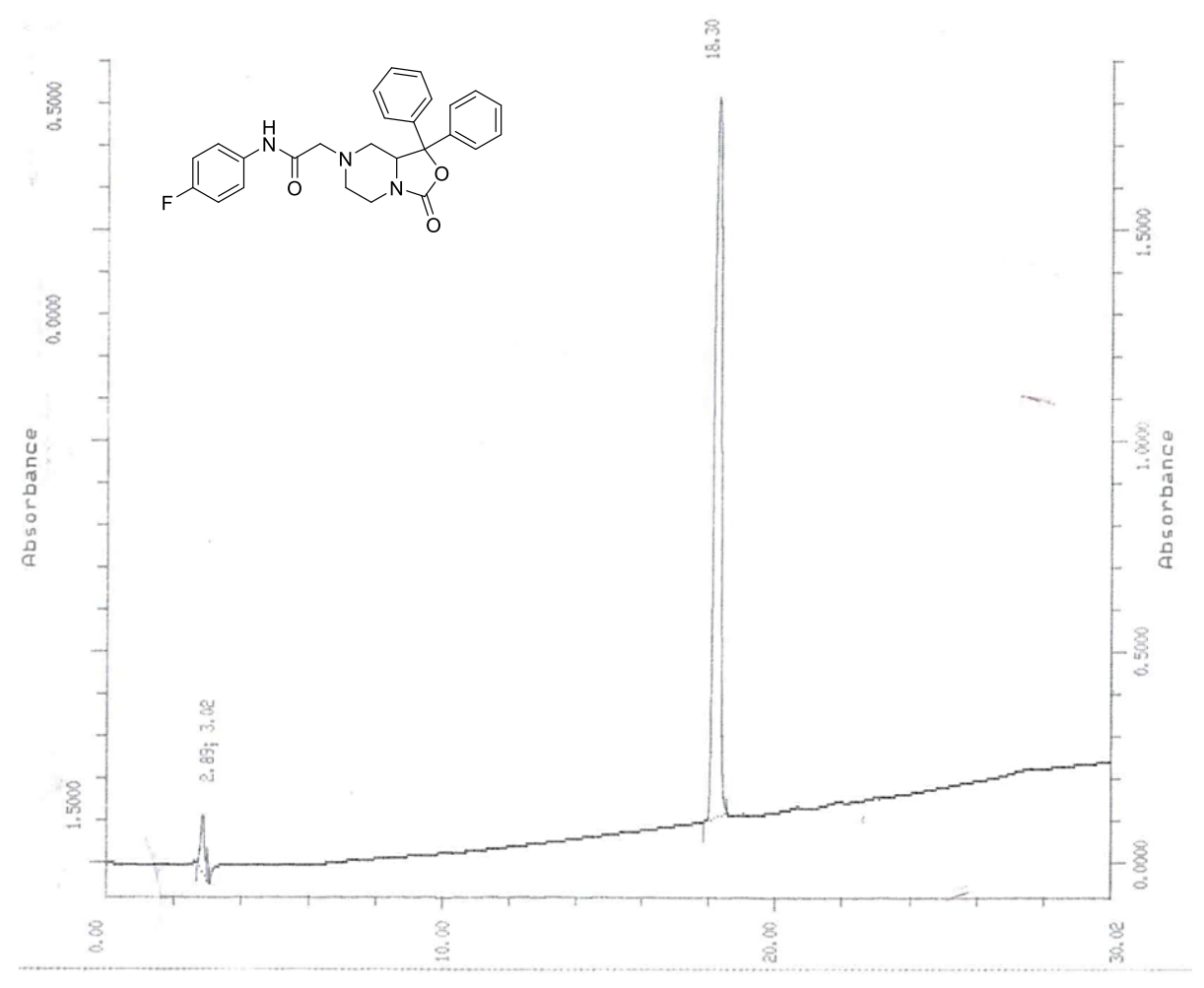

Compound 14

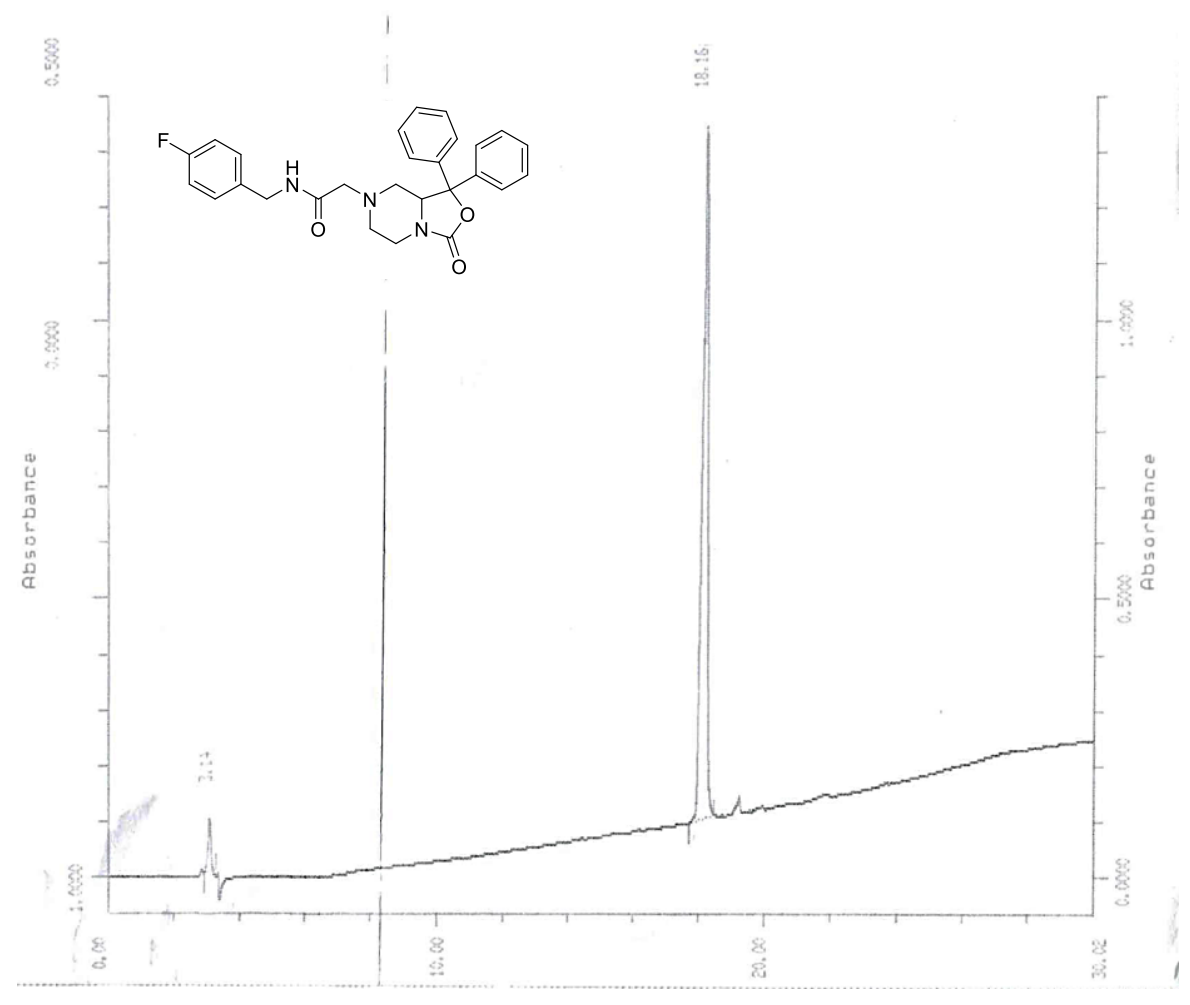

S32 


\section{Compound 15}

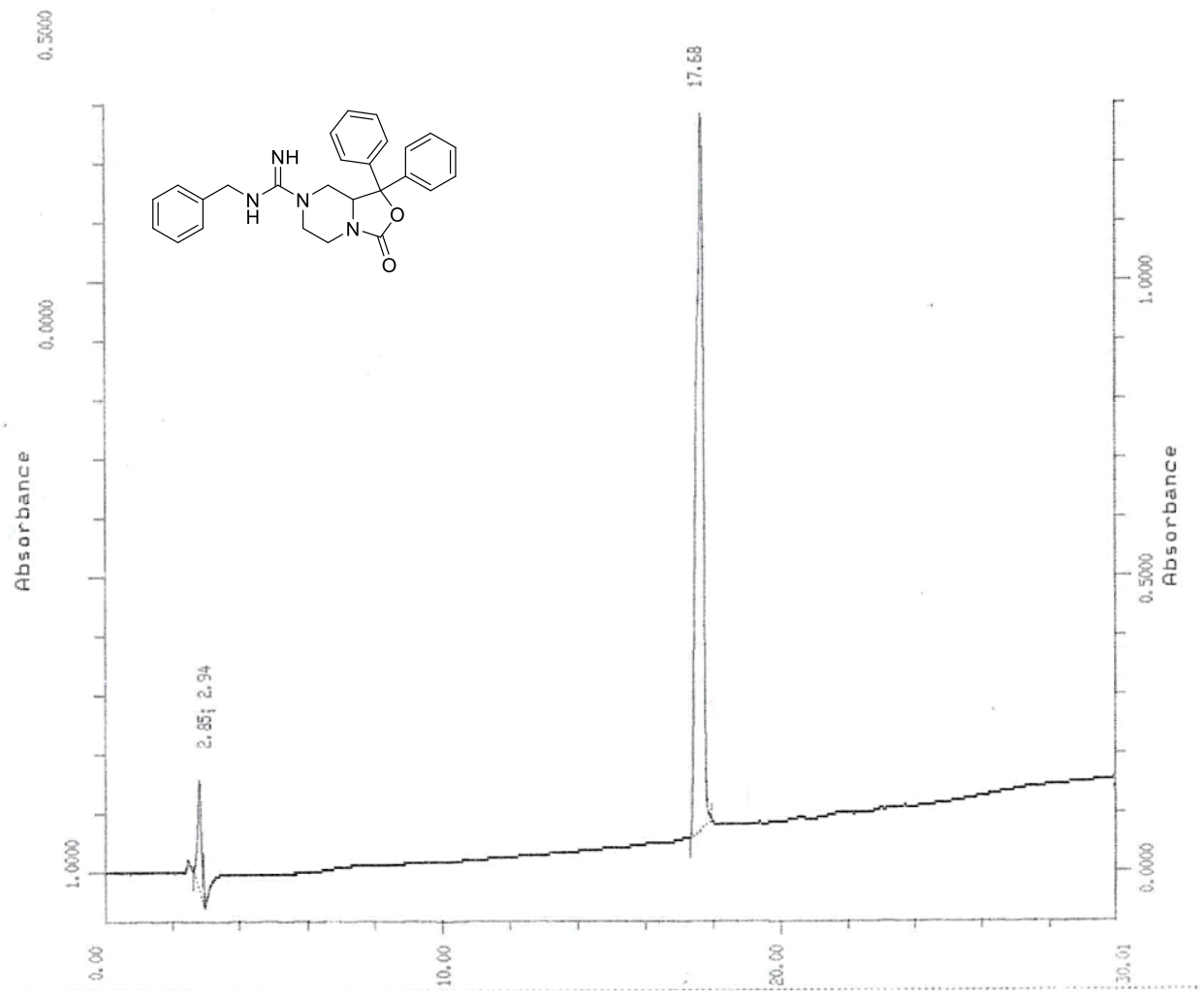

\section{Compound 16}

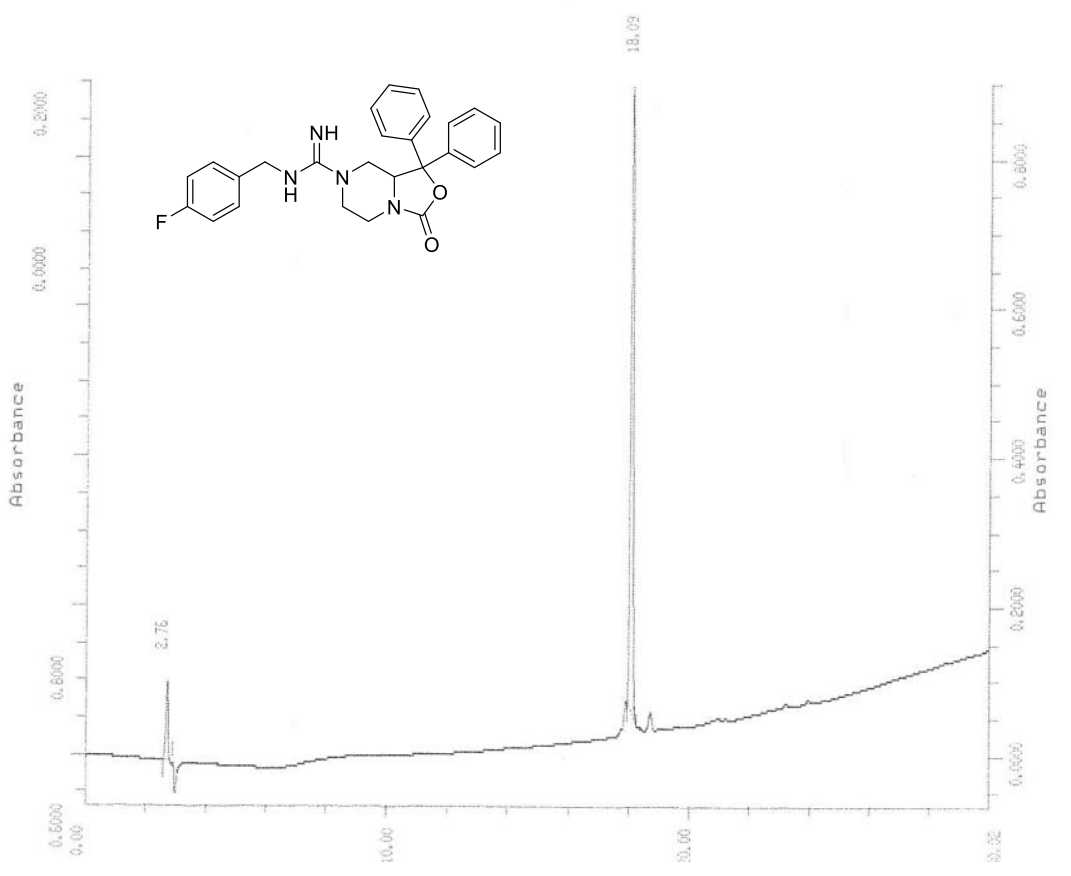




\section{Compound 17}

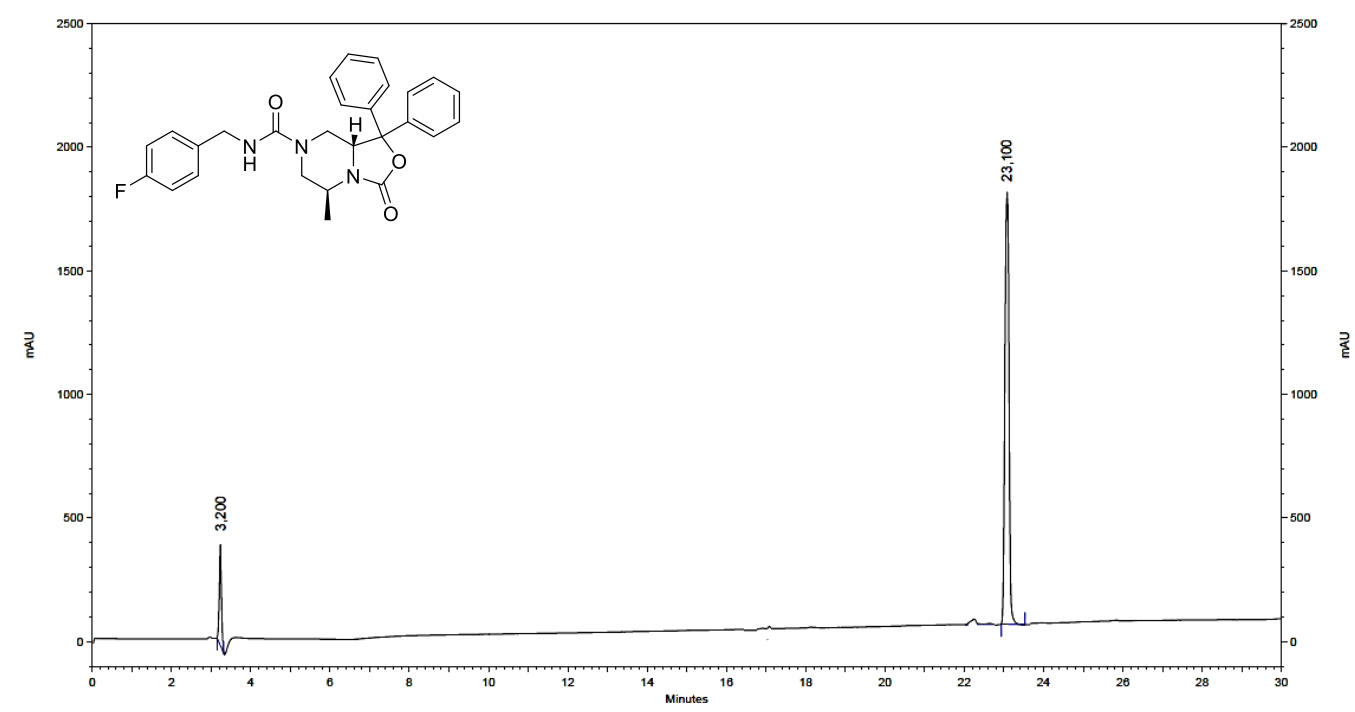

\section{Compound 18}

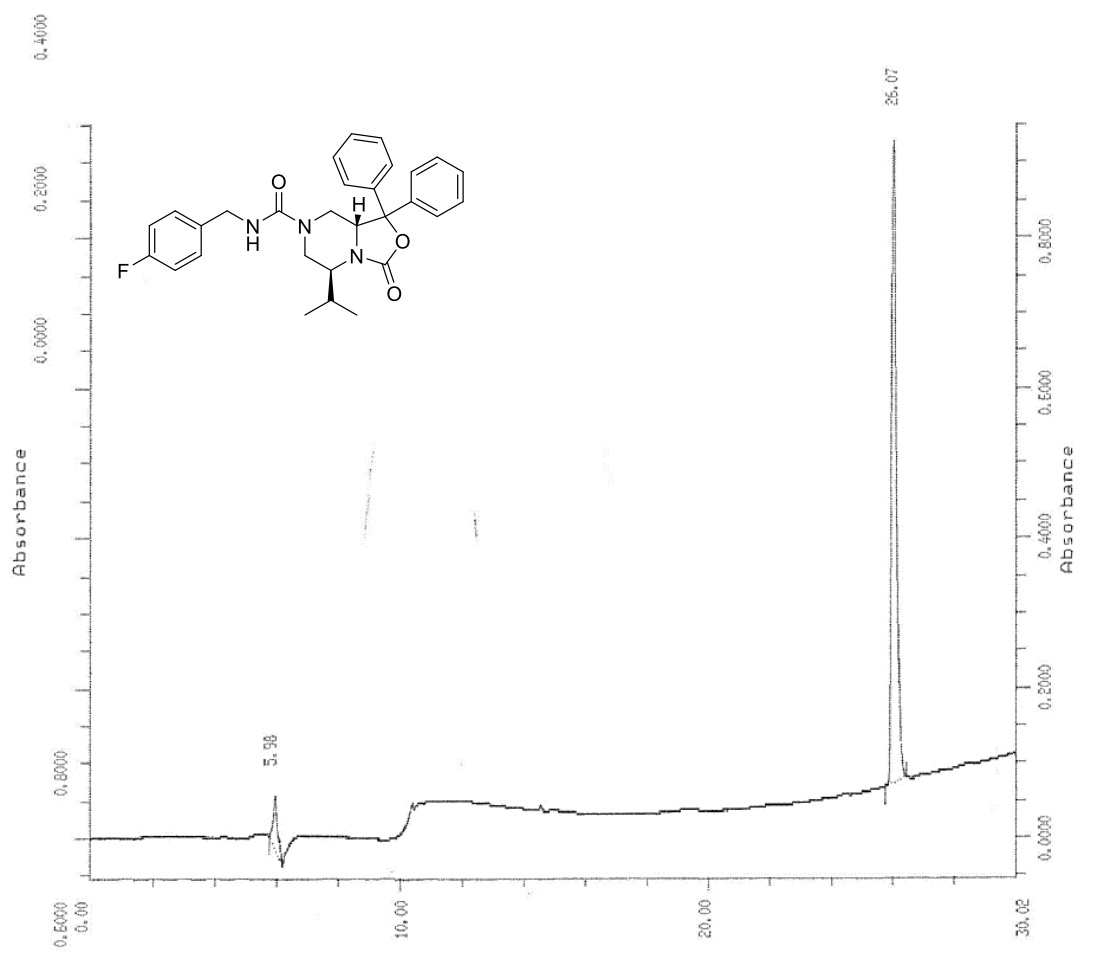




\section{Compound 19}

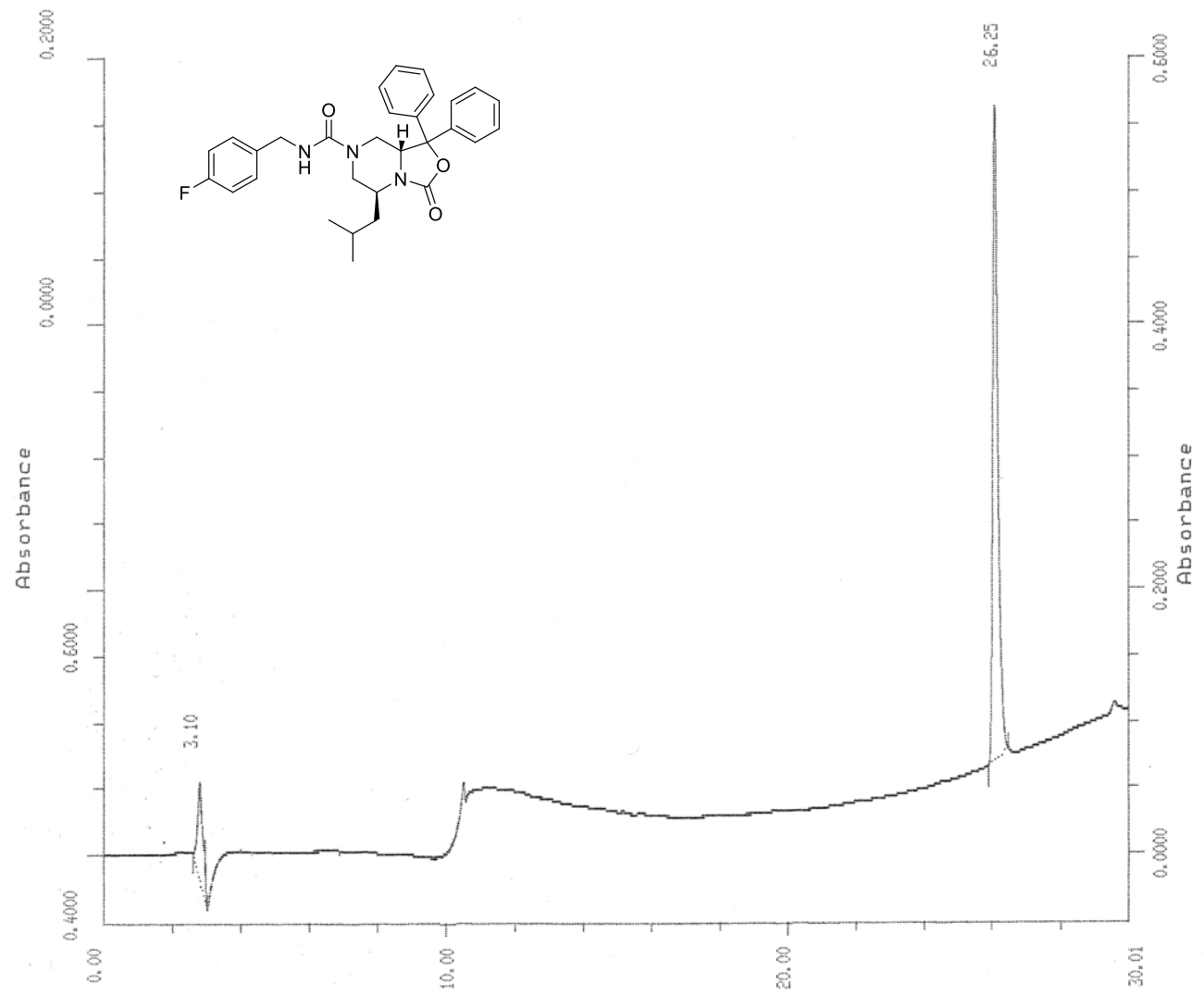

Compound 20

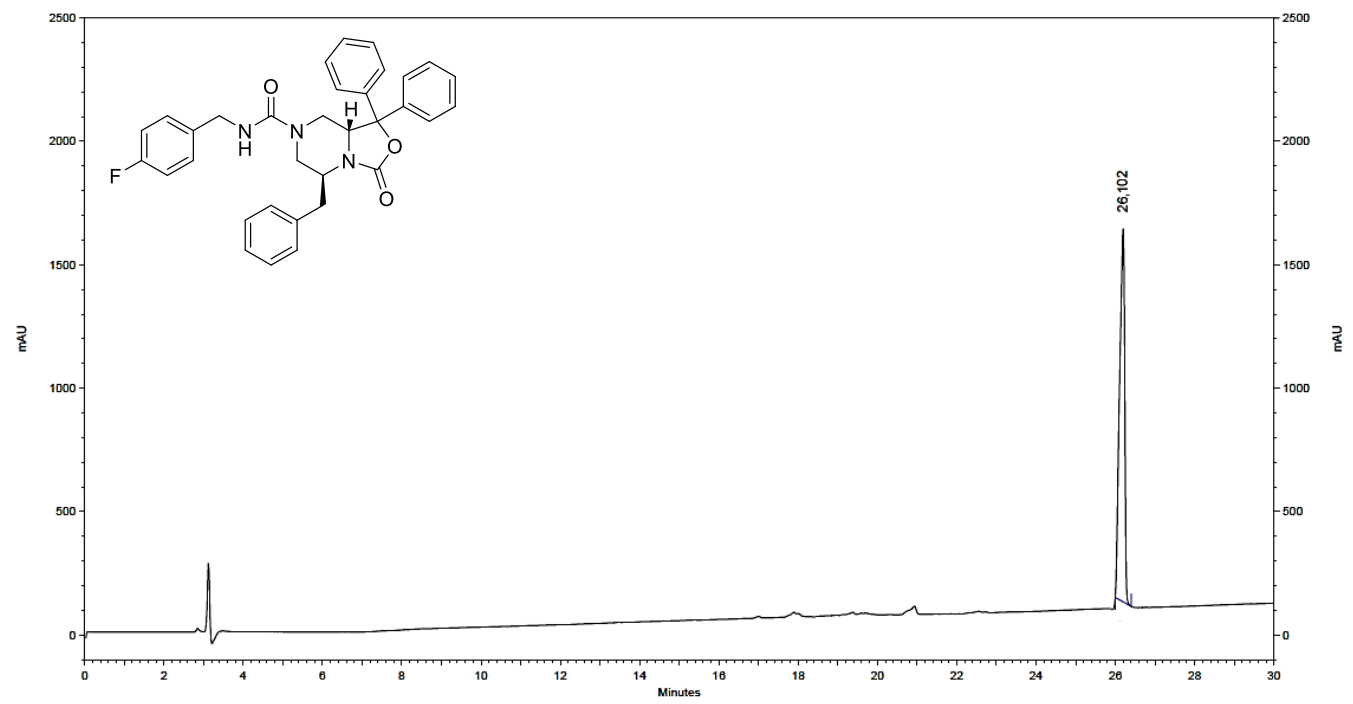




\section{Compound 21}

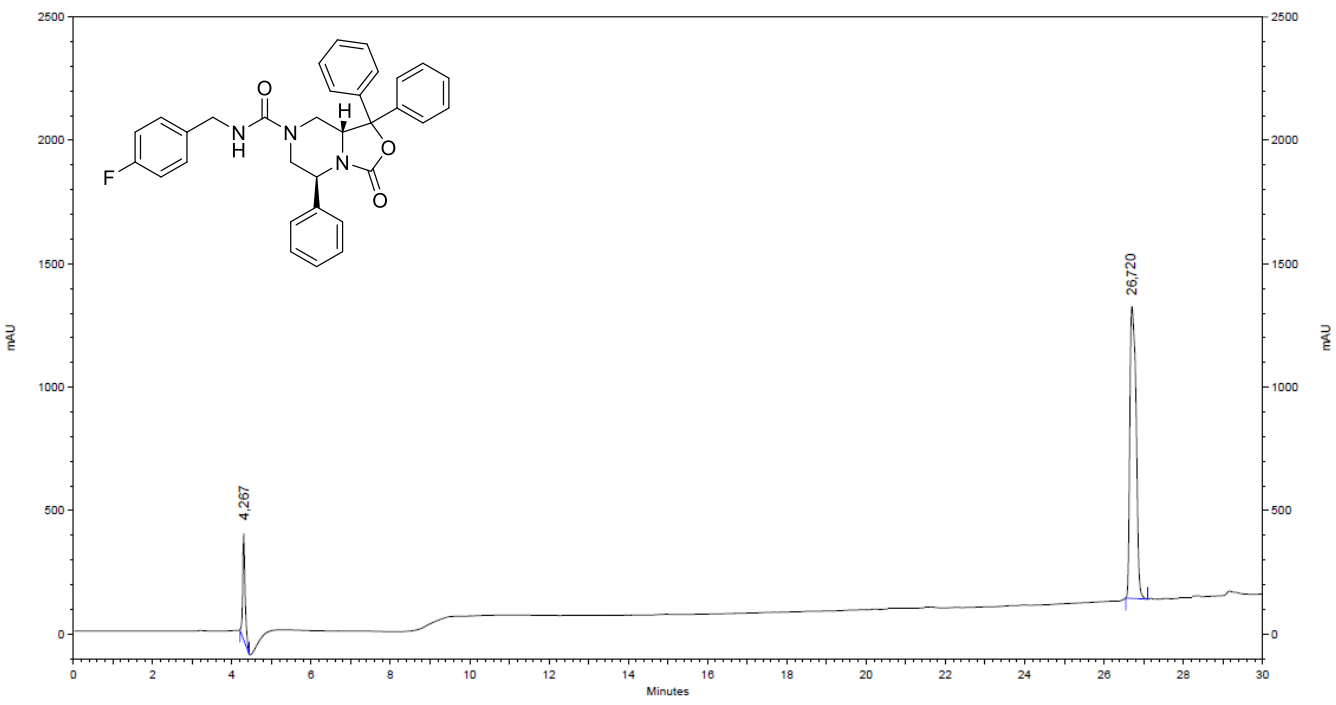

